\title{
EN-ROUTE AIRSPACE CAPACITY AND TRAFFIC FLOW ENHANCEMENT USING GENETIC ALGORITHMS
}

\author{
Ramazan Kürşat ÇEÇEN ${ }^{1, *}$, Cem ÇETEK ${ }^{1}$ \\ ${ }^{1}$ Department of Air Traffic Control, Anadolu University, Eskişehir, Turkey
}

\begin{abstract}
Air transportation industry has gone under a rapid and continuous growth for the last four decades. International Civil Aviation Organization (ICAO) and aircraft manufacturers anticipate that annual growth rate of air traffic will be 4.5-5.1\% until 2030 . Airspace capacity management becomes more critical for the safety, efficiency and sustainable growth of the industry. Enroute areas cover the largest portion of the controlled airspace and are subdivided into small segments referred to as 'en-route sectors'. Each sector is usually monitored and controlled by a single air traffic controller in the relevant Area Control Center (ACC). When air traffic demand reaches or exceeds the available en-route sector capacity, serious aircraft delays occur at airports or in airspace. When air traffic demand reaches to the available en-route sector capacity, serious aircraft delays occur at airports or in airspace. These delays lead not only to system-wide congestions but also interruptions in air traffic services, airline flight schedules and airport operations. Therefore, these interruptions result in increased operational costs, passenger dissatisfaction and air traffic controller workload. This study presents a multiple entry point assignment model based on a genetic algorithm to minimize delays and increase throughput of a generic high-altitude en-route sector. The proposed approach intends to provide a framework for a decision support system based on flexible and dynamic direct route utilization for air traffic and capacity management. The available single entry point sector configuration and its multiple entry point assignment alternatives were compared for various traffic scenarios. Multiple entry point configurations provided up to $10 \%$ increase in throughput and significant reductions in average delay per aircraft compared to the single point entry configuration.
\end{abstract}

Keywords: Air traffic flow and capacity management, Airspace delay reduction, Sector entry-point assignment, Aircraft conflict resolution, Genetic algorithms

\section{INTRODUCTION}

Air transportation is not only a large-scaled service production industry supporting the worldwide economic and social growth but also a key driver for the development of local industries such as tourism, international commerce and construction. Despite economic recessions, fluctuations in oil prices and security threats, air travel demand has been increasing regularly for the last four decades [1]. International Civil Aviation Organization (ICAO) and aircraft manufacturers anticipate that annual growth rate of air traffic will be 4.7-5.1\% until 2030 [2-4]. In order to handle this continuous growth, airspace capacity management becomes more critical for the safety, efficiency and sustainable growth of the industry.

Air Traffic System (ATS) is a service production system including all necessary airspace, technical equipment, aircraft and human resources to provide safe, efficient and economic air traffic flow [5]. In this system, airspace can be defined as any part of the earth's atmosphere used by aircraft. Airspaces can be categorized as controlled, uncontrolled and special airspaces according to air traffic services provided and flight requirements. Controlled airspace is an airspace with a defined boundaries in which relevant air traffic control services are provided in accordance with the airspace classifications described by ICAO such as A, B, C, D and E [6]. In order to provide air traffic services efficiently, large controlled airspaces can be separated into airport zones (CTR), terminal control areas (TMA) and en-route areas [7] as presented in Figure 1 [8]. En-route areas cover the largest portion of the controlled airspace and surround terminal airspaces. These areas can be divided in vertical as low and high altitude en-route

*Corresponding Author:ramazankursatcecen@anadolu.edu.tr 
areas as well as each of these areas can be subdivided into small segments referred to as "en-route sectors'. Air traffic within each en-route sector is usually monitored and controlled by a single air traffic controller in the relevant Area Control Center (ACC).

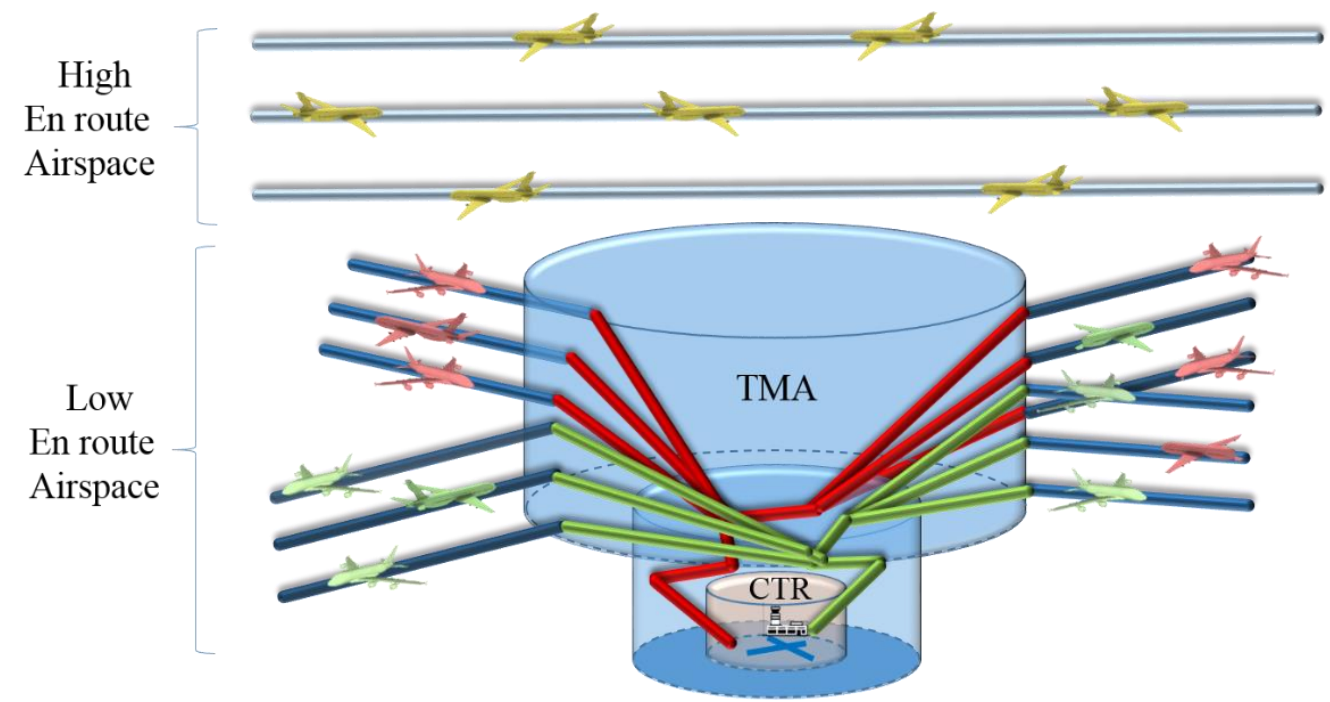

Figure 1. Structure of the controlled airspace [8]

When air traffic demand reaches or exceeds the available en-route sector capacity, serious aircraft delays occur at airports or in airspace. These delays lead to system-wide congestions and interruptions in air traffic services, airline flight schedules and airport operations, and therefore result in increased operational costs, passenger dissatisfaction and air traffic controller workload [9].

Numerous methods have been presented to solve sector capacity problem and provide more efficient use of en-route airspace. There are two main approaches to regulate sector capacities: air traffic flow management (ATFM) and airspace sectorization studies. ATFM methods utilize various techniques such as ground holding, airborne holding and re-routing in order to minimize delays and congestions of the current sectors [10].

Ground holding techniques impose intentional ground delays on certain aircraft to regulate air traffic flow and reduce delays and congestions in the air. Therefore, predicted delay in en-route and terminal airspace sectors are transferred to airports. Ground holding concept was first described by Odoni [11]. Since then, different methods have been implemented to solve this problem such as deterministic single airport models [12], stochastic linear programming for static [13] and dynamic [14] cases, 0-1 integer programming models for multiple airport networks [15] and dynamic stochastic integer programing with multiple decision stages [16].

Airborne holding, on the other hand, focuses on en-route conflict resolution and aircraft sequencing problems using speed adjustment and vectoring techniques to manage air traffic flow through airspace sectors efficiently. Various airborne holding methods have been introduced such as offset heading changes based on protected zone priorities [17], heading change avoidance model for intersecting traffic flows [18], en-route speed adjustment model for arriving aircraft to terminal airspaces [19], en-route maneuver models based on evolutionary algorithm and constraint programming [20], and en-route speed control methods using realistic economic maneuvers [21] and multi-objective integer programming [22].

Re-routing approaches involve with the assessment of route alterations based on occupancy of airspace sectors. Bertsimas and Patterson [23] proposed 0-1 integer programming model using re-routing and ground holding techniques to evaluate impacts of multiple airport terminal airspaces on en-route 
airspace sectors. They also presented a re-routing model based on dynamic, multi-commodity network flow approach [24]. Dell'Olmo and Lulli [25] developed a two-level hierarchical model including air routes networks and optimal traffic routes using both mixed integer programming and heuristic algorithms. Agusti et al. [26,27] developed re-routing approaches for large-scaled deterministic and stochastic ATFM problems.

Airspace sectorization studies mainly deal with changing sector geometries and route structures based on traffic density and air traffic controller workload in order to increase the airspace system capacity. Delayhe et al. [28] used genetic algorithms to find optimal sector grouping. Yousefi et al. [29] built a model to optimize airspace sector according to controller workload. Mithcell et al. [30] proposed a dynamic airspace configuration based on geometric techniques. Xue [31] developed a model based on voronoi diagrams and genetic algorithms. Basu et al. [32] presented an automatic sectorization model using geometric algorithms. Zhang et al. [33] provided a sectorization model that based on weighted graph spectral bisection method.

This study presents a multiple entry point assignment model based on a genetic algorithm to minimize delays and increase throughput of a generic high-altitude en-route sector. The algorithm searches for optimal conflict geometries for given intersecting traffic flows for different number of entry points and percentages of aircraft types. The effects of spacing between adjacent entry points were also analyzed on the throughput and delays. The proposed approach intends to use more flexible direct route configuration without changing the sector geometry and provide a framework for a decision support system for air traffic flow and capacity planning and management. Conflict resolution methods are limited in the horizontal plane to maintain aircraft flow and management safely within the pre-defined separation minima.

This approach differs from the previous ones developed for en-route capacity enhancement due to its optimal multiple entry point assignment process. No similar multiple entry point assignment model for en-route has been found in the literature. The only study regarding multiple entry point approach was developed to regulate air traffic flow to terminal control areas using a simulation-based dynamic entry point assignment model by Aybek Cetek [8].

\section{PROBLEM DESCRIPTION}

The capacity of an en-route airspace sector can be defined as the maximum number of aircraft served over a given period of time. En-route sector capacity depends on sector geometry, route structure, number of flight levels, separation minima, ATC procedures, accuracy of navigation equipment, weather conditions, human factors, aircraft performance categories and their distribution in the total traffic demand. As long as these factors remain unchanged, the capacity will be a constant value. The traffic demand, on the other hand, can fluctuate annually, seasonally and even daily.

Capacity problem appears as the traffic demand over a given period of time approaches to capacity limits of the sector and leads to delays in flight operations. These delays not only affect flight operations within the specified hour(s) adversely but also disturb the flight schedules in the following hours. Delays in the system can be handled without serious disruption in the traffic flow up to a critical limit. This limit is known as predefined acceptable delay or level-of-service per flight. The number of flight served per hour corresponding to this limit is referred to as practical capacity (Figure 2). The airspace sector becomes congested when its practical capacity is exceeded by the actual demand, and average delay per flight goes beyond the acceptable limit. As congestions in the sector grow, they lead to propagation of delays through neighboring sectors and eventually over the entire system. When the maximum (theoretical) capacity is achieved, the sector is said to be saturated which means no more aircraft can be accepted within the concerned period of time. 


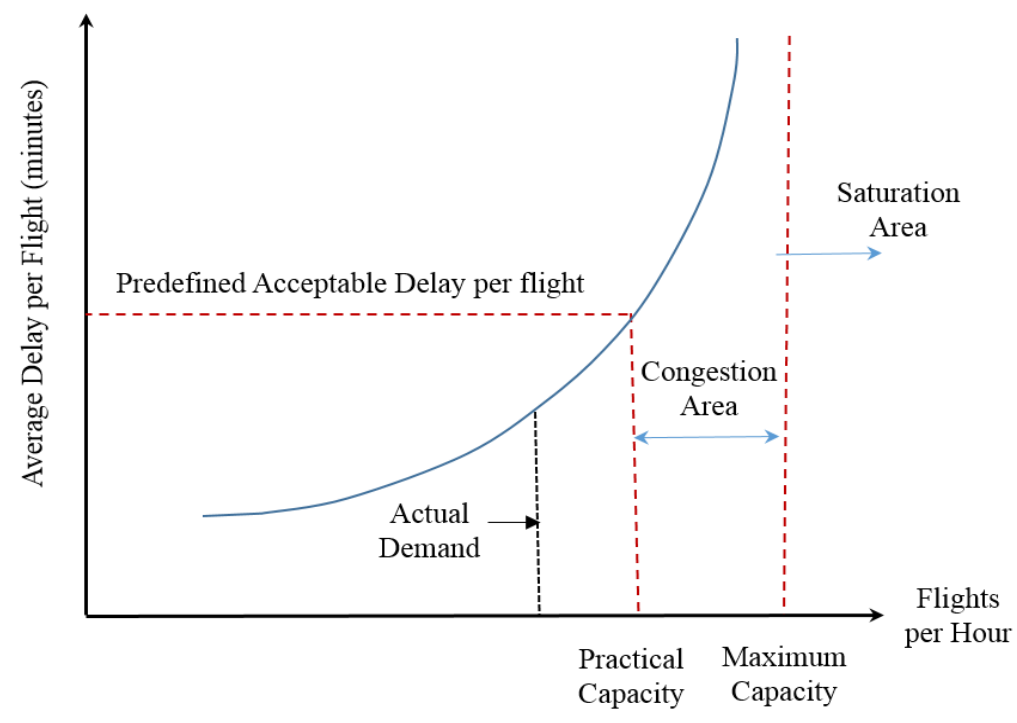

Figure 2. Relationship between demand, capacity and delay [34]

Airborne delays are primarily affected by separation minima, the shortest distance to be maintained between aircraft for flight safety. These minima are determined by Air Navigation Service Providers (ANSPs) according to the accuracy of onboard and ground navigation and surveillance equipment, aircraft wake turbulence categories and ATC procedures. Aircraft should be separated by $1000 \mathrm{ft}$. vertically and $5 \mathrm{NM}$ horizontally in the radar controlled en-route airspace [35]. Depending on the circumstances, both time-based and distance-based separations can be implemented in horizontal plane. When aircraft approaches each other less than these separation minima, airborne conflicts occur between aircraft. These conflicts can be classified as head-on, crossing and overtaking conflicts depending on the geometry of their trajectories (Figure 3). In order to resolve these conflicts in the horizontal plane, airborne delays are imposed on aircraft using a proper combination of vectoring and/or airspeed adjustment. Higher airborne delay results in the decrease in the capacity of the sector.

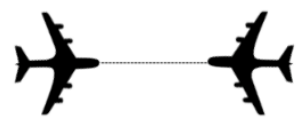

(a)

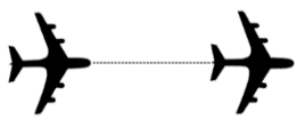

(b)

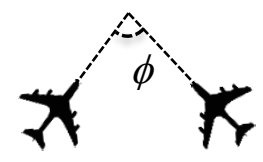

(c)

Figure 3. Conflict geometries: (a) Head-on conflict, (b) Overtaking conflict, (c) Crossing conflict

\subsection{Baseline En-Route Sector Model}

An en-route sector (Figure 4) was modeled as a rectangular volume of airspace with two intersecting linear routes between entry and exit points at each flight level between $29.000 \mathrm{ft}$ to $37000 \mathrm{ft}$ of altitude. 


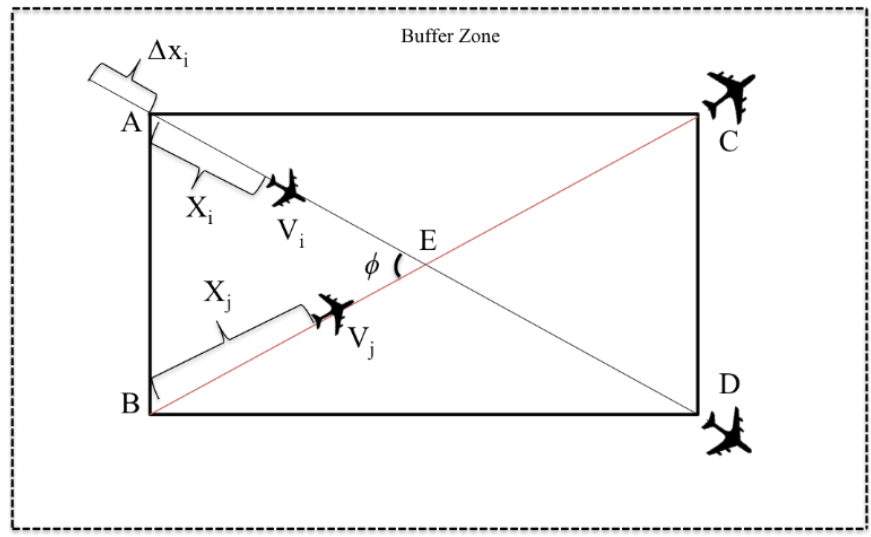

Figure 4. A basic shape of a Sector Model

Two incoming aircraft flows in southeast and northeast direction enter the sector from entry point A and B, respectively. Aircraft leave the sector from point C and D and their routes cross at point E. Entry, exit and intersection points can be defined using either navigational aids or waypoints. The sector is surrounded by a buffer zone in which aircraft are allowed to have airborne delays before reaching to their entry points. In order to formulate the capacity and total delay of the sector, the following assumptions and constraints were imposed on the model:

(1) Aircraft are considered as point masses within a cylindrical protection zone with $5 \mathrm{NM}$ diameter and $1000 \mathrm{ft}$ height (Figure 5). This protection zone should not be violated by other aircraft along the entire flight.

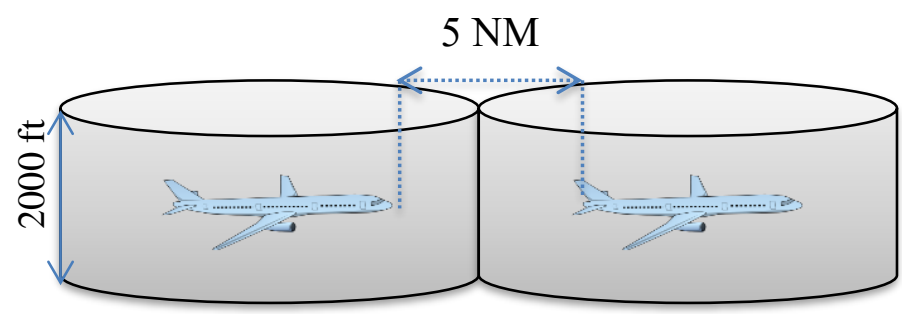

Figure 5. En-route aircraft separation

(2) No heading, airspeed and altitude change of aircraft are allowed within the sector boundaries.

(3) Aircraft are classified in three different performance groups such as regional jets, narrow body jets and wide body jets using a clustering technique based on aircraft performance and traffic coverage data $[36,37]$. Table 1 each performance group has different airspeed for each level.

Table 1. Average true airspeeds for aircraft performance groups

\begin{tabular}{|c|c|c|c|c|c|}
\cline { 2 - 6 } \multicolumn{1}{c|}{} & \multicolumn{5}{c|}{ TRUE AIRSPEEDS (KTS) } \\
\hline \hline $\begin{array}{c}\text { Aircraft Performance } \\
\text { Group }\end{array}$ & FL290 & FL310 & FL330 & FL350 & FL370 \\
\hline \hline Regional Jet & 415 & 418 & 419 & 415 & 421 \\
\hline Narrow Body Jet & 448 & 451 & 453 & 449 & 446 \\
\hline Wide Body Jet & 478 & 479 & 476 & 471 & 469 \\
\hline
\end{tabular}


(4) The percentage share of each aircraft performance group within the traffic flow is known.

(5) Flight tracks of each aircraft are exactly known. Effects of weather conditions and navigation inaccuracies on aircraft positions are ignored.

(6) Exponential probability distribution is used to determine inter-arrival times of aircraft entering to the sector. The mean of this distribution is set 60 seconds in order to ensure that the sector capacity lies in the congestion area. No simultaneous aircraft entries are allowed to the sector.

(7) Traffic shares of southeast and northeast traffic flows are known.

(8) In case of potential conflict between aircraft pairs, airborne delay will be imposed on the aircraft with a later entry time to maintain safe separation minima.

Hourly throughput of each flight level in the sector, $C_{F L}$ is described as follows:

$$
C_{F L}=\frac{3600}{\frac{\sum_{j=1, i=j+1}^{N_{\max }-1} \Delta t_{i j}}{N_{\max }}}
$$

where $\Delta t_{i j}$ is the inter-arrival time between aircraft pair (i.e. aircraft $i$ and $j$ where $i>j$ ) and $N_{\max }$ is the maximum traffic demand. Inter-arrival time between the two consecutive aircraft can be formulated as:

$$
\Delta t_{i j}=\left(t_{i}+d_{i}\right)-t_{j}
$$

where $t_{i}$ and $t_{j}$ are the sector entry time of trailing aircraft, $i$ and leading aircraft, $j$, respectively $\left(t_{i}, t_{i} \epsilon\right.$ $\left.\left[t_{0}, t_{f}\right]\right)$ and $\mathrm{d}_{\mathrm{i}}$ is the amount of delay for trailing aircraft to resolve the possible conflicts. In order to obtain the maximum throughput of the flight level, aircraft flying on dependent (i.e. crossing or coincident) routes should be free of conflicts. Therefore, they should satisfy the following constraint:

$$
\begin{gathered}
R(t)=\left(\left(\mathrm{X}_{\mathrm{i}}+x_{i}\right) \quad V_{i} \cdot t\right)^{2}+\left(\begin{array}{ll}
X_{j} & V_{j} \cdot t
\end{array}\right)^{2} \\
2\left(\left(\mathrm{X}_{\mathrm{i}}+x_{i}\right) \quad V_{i} \cdot t\right)\left(X_{j} \quad V_{j} \cdot t\right) \cos \left({ }_{i j}\right) \geq S_{\text {min }}
\end{gathered}
$$

where $X_{i}$ and $X_{j}$ are distances flown by aircraft, $i$ and aircraft, $j$ with respect to the entry point, respectively; $V_{i}$ and $V_{j}$ are true airspeeds of aircraft, $i$ and aircraft, $j$, respectively; $\phi_{i j}$ is the relative angle between routes of aircraft, $i$ and aircraft, $j ; \Delta x_{i j}$ is the initial separation distance of trailing aircraft before sector entrance; and $S_{\min }$ is the minimum horizontal safe separation distance between aircraft $i$ and $j$. Therefore, the amount of delay $\left(d_{i}\right)$ to be imposed on the trailing aircraft can be calculated using the following formula:

$$
d_{i}=\frac{\Delta x_{i}}{V_{i}}
$$

Then the total delay of the flight level $D_{F L}$ is estimated as the sum of delays per aircraft, $d_{i}$ such that:

$$
D_{F L}=\sum_{i=1}^{N_{\max }} d_{i}
$$

\subsection{The Proposed Model: En-Route Sector with Multiple Entry Points}

New entry points spaced with equal intervals were considered in the proposed model in order to increase the throughput of the sector as well as decrease airborne delays. Aircraft in the traffic flows can be assigned to one of the entry points around the corner of the sector (Figure 6). Therefore, conflict geometries between each aircraft pair can be altered and the required airborne delay can be reduced using different entry point combinations. The optimal assignment schedule maximizing the throughput was searched using a genetic algorithm for different operational scenarios. 


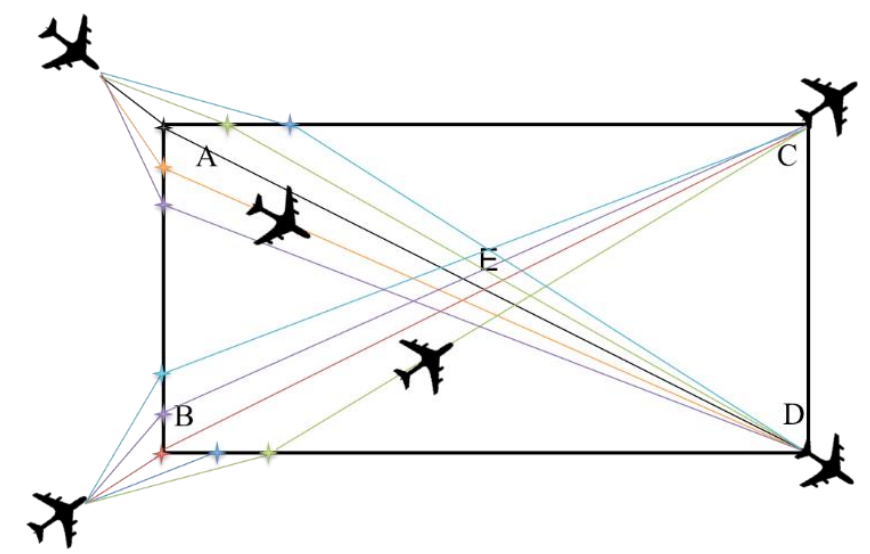

Figure 6. En-Route Sector with multiple entry points

The main input parameters of the model are total flight demand (i.e. number of traffic entering to the sector), direction of traffic flows (i.e. northwest and southwest), traffic mix (i.e. percentage of wide body aircraft, narrow body aircraft and regional jet within the demand), the number of entry points, $e_{A}$ and $e_{B}$ for each corner A and B, respectively and spacing between adjacent entry points.

The number of entry points, $e_{A}$ and $e_{B}$, were assumed equal and set to $3,4,5$ and 7 points, respectively. The spacing between each adjacent entry points was considered equal and set to values between 1 to 5 nm.

\section{ALGORITHM}

Genetic algorithms (GAs) is an optimization technique based on the evolution principles such as natural selection, crossover and mutation, and used for solving both constrained and unconstrained problems [38]. GAs have been implemented to different types of transportation problem successfully.

As a nature-inspired algorithm, GA seeks for the fittest chromosomes having the better chance of survival thus the next generations will be healthier since they are generated from stronger parents. At the each iteration, the average fitness value of population rises. In GA, first an initial population is created randomly. Next, the fitness values are evaluated for each chromosomes according to these fitness values, selection process is initiated to determine which chromosomes will be eliminated and which chromosomes will be used for the next step.

There are certain types of selection methods such as elitism, tournament selection, rank selections, roulette wheel selection and steady state selection. In the elitism method, fitness values are key factor to choose parents of a next generation. All chromosomes are compared and the fittest ones are transferred to the next generation in every iteration.

Upon the completion of the selection step, selected chromosomes are randomly matched using crossover process. The crossover point or points are also randomly determined. There are basic methods for selection of the chromosome: one-point crossover, two-point crossover (Figure 7), uniform crossover and half uniform crossover and three-parent crossover.

\begin{tabular}{|l|l|l|l|l|l|l|l|l|l|l|l|l|l|l|}
\hline 0 & 1 & 1 & 0 & 0 & 1 & 0 \\
0
\end{tabular}
\begin{tabular}{|l|l|l|l|l|l|l|l|l|l|l|l|l|l|l|}
\hline 0 & 1 & 1 & 0 & 1 & 1 & 0 \\
\hline 0 & 1 & 1 & 0 & 1 & 0 & 0 \\
\hline
\end{tabular}

Figure 7. Two-Point Crossover 
Mutation operation starts follow after crossover process. The aim of the mutation is to ensure genetic diversity of population. Because of the mutation, brilliant chromosomes randomly may occur. There are certain types of mutation such as bit string mutation, flip bit mutation (Figure 8), promotes mutation and demotes mutation.

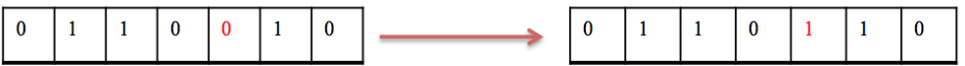

Figure 8. Mutation Operation

In this study, fitness function is chosen as the hourly sector capacity. After estimating the hourly capacity, the corresponding average delay per aircraft was also calculated. The GA (Figure 9) is coded using MATLAB programming language. First, size of population, the maximum number of iterations and probability of crossover and mutation are selected as $10,800,80 \%$ and $5 \%$, respectively prior to the generation of initial population.

Sector throughput estimation process is presented in Figure 10. In the first step, the algorithm receives two input regarding flight and entry point configuration from flight database and sector geometry lookup table, respectively. Flight data of each aircraft $(j)$ include airspeed $\left(V_{j}\right)$, scheduled sector entry time $\left(S E T_{j}\right)$ and flight route $\left(R_{i j}\right)$ information while entry point configuration data consists of user-defined sector parameters such as number of entry points $\left(E_{k}\right)$ and horizontal spacing between adjacent entry points $(s)$. According to entry point assignments and scheduled sector entry times, conflict detection step checks for potential crossing and overtaking conflicts sequentially in the horizontal plane between each aircraft pair ( $i$ and $j$ ) within the sector. If a conflict is detected, conflict resolution step calculates necessary airborne delay and implements it to the trailing aircraft. In the next step, the sector entry time of the delayed aircraft is updated and its delay time is recorded in the system memory. These steps are repeated for all aircraft in order to estimate the fitness function (throughput) and corresponding total sector delay.
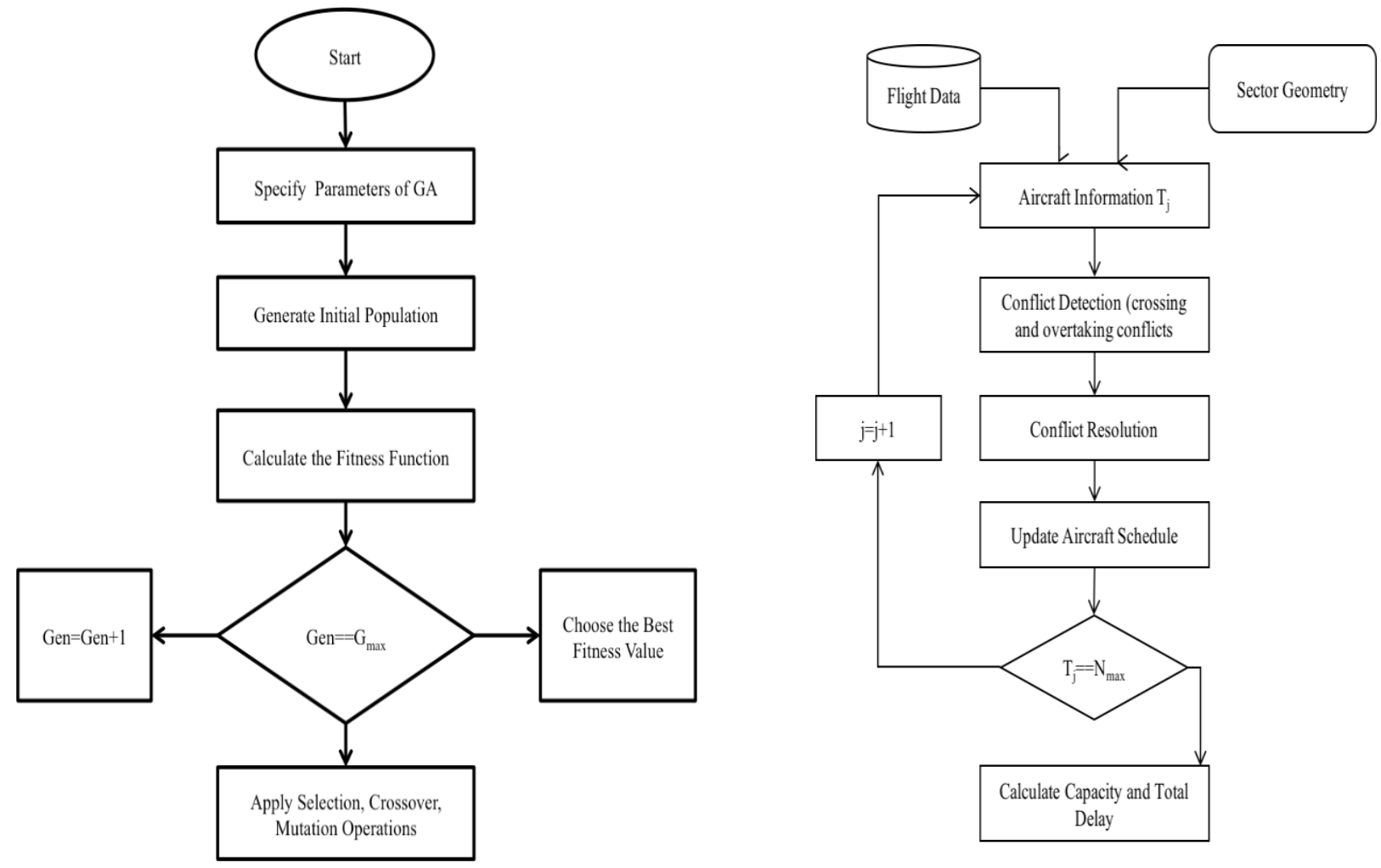

Figure 9. Genetic algorithms flow chart

Figure 10. Sector throughput estimation process 


\section{SCENARIOS}

Four user-defined parameters were chosen to evaluate the capacity and delays of the given en-route airspace sector such as aircraft performance categories, traffic type mix (TM\%), inter-arrival time $\left(\Delta t_{i j}\right)$, and flight routes $\left(n_{r}=1,2\right)$. Aircraft types are classified under three different performance categories, namely regional jets $(R J)$, narrow body aircraft $(N B)$ and wide body aircraft $(W B)$, according to their cruising airspeeds for given flight levels (Table 1). Representative cruising airspeed of each category was calculated using weighted average of aircraft types based on coverage of European traffic in 2013 [37].

Traffic type mix is defined as the percentage ratio of wide body aircraft category to the entire aircraft population entering to the sector. The percentage mix of regional jet category is assumed constant and equal to $10 \%$ for each scenario. Inter-arrival times of aircraft entering to the sector were modeled using exponential distribution with a scale parameter $(\beta)$ of one minute. Two direct flight routes, intersecting angle $(\phi)$ was considered during analysis.

After computation of delays for each aircraft pair, throughput and delay analysis were performed for the case of single entry point per air traffic flow in the baseline scenario, first. Then the effects of the number of entry points and spacing between them were analyzed in two different alternative scenarios. In the first alternative scenario, capacity and delay analysis were accomplished for different number of input entry points $\left(n_{e p}\right)$ per traffic flow such as $3,4,5$ and 7 . Entry points were placed with a fixed $5 \mathrm{NM}$ distance-spacing $(s)$ from each other for this scenario. In the second alternative scenario, the same analysis was repeated for different spacing values ranging between 1 to $5 \mathrm{NM}$. Input parameters of each scenario were summarized in Table 2.

Table 2. Input parameters of baseline and alternative scenarios

\begin{tabular}{|c|c|c|c|c|c|c|}
\hline Scenario & Cases & FL & TM (\%) & $\mathbf{n}_{\mathbf{r}}$ & $\mathbf{n}_{\mathrm{ep}}$ & s (NM) \\
\hline Baseline & - & \multirow{9}{*}{ FL290-370 } & \multirow{5}{*}{$\begin{array}{c}\mathrm{WB}=20-70 \% \mathrm{RJ}= \\
10 \%\end{array}$} & \multirow{9}{*}{2} & 1 & - \\
\hline \multirow{4}{*}{ Alternative 1} & A & & & & 3 & \multirow{4}{*}{$5 \mathrm{NM}$} \\
\hline & $\mathrm{B}$ & & & & 4 & \\
\hline & $\mathrm{C}$ & & & & 5 & \\
\hline & $\mathrm{D}$ & & & & 7 & \\
\hline \multirow{4}{*}{ Alternative 2} & A & & \multirow{4}{*}{$\begin{array}{l}\mathrm{WB}=20 \% \\
\mathrm{NB}=70 \% \\
\mathrm{RJ}=10 \%\end{array}$} & & 3 & 1 to $5 \mathrm{NM}$ \\
\hline & B & & & & 4 & 1 to $5 \mathrm{NM}$ \\
\hline & $\mathrm{C}$ & & & & 5 & 1 to $5 \mathrm{NM}$ \\
\hline & $\mathrm{D}$ & & & & 7 & 1 to $5 \mathrm{NM}$ \\
\hline
\end{tabular}

\section{RESULTS}

\subsection{Baseline Scenario: Single Entry Point}

The impact of traffic mix on the throughput and average delay of each flight level are presented in Figure 13 and 14, respectively. As the percentage of wide body aircraft increases in the total traffic flow, throughputs decreases (Figure 11) while average delay increases (Figure 12) up to the critical value of $60 \%$. Until this critical value, the increasing share of wide body aircraft raises the probability of higher initial separation distance, $\Delta x$ in order to ensure the safe separation minima. Therefore, higher average delays occur due to higher initial separations under $60 \%$ traffic mix. When the wide body percentage is over its critical value of $60 \%$, the throughput increases by $4-6 \%$ for each flight level because the increase 
in the average airspeed of traffic flows recovers delays induced by the increased traffic mix. Upper flight levels have higher throughput and lower average delays because of their higher average airspeeds.

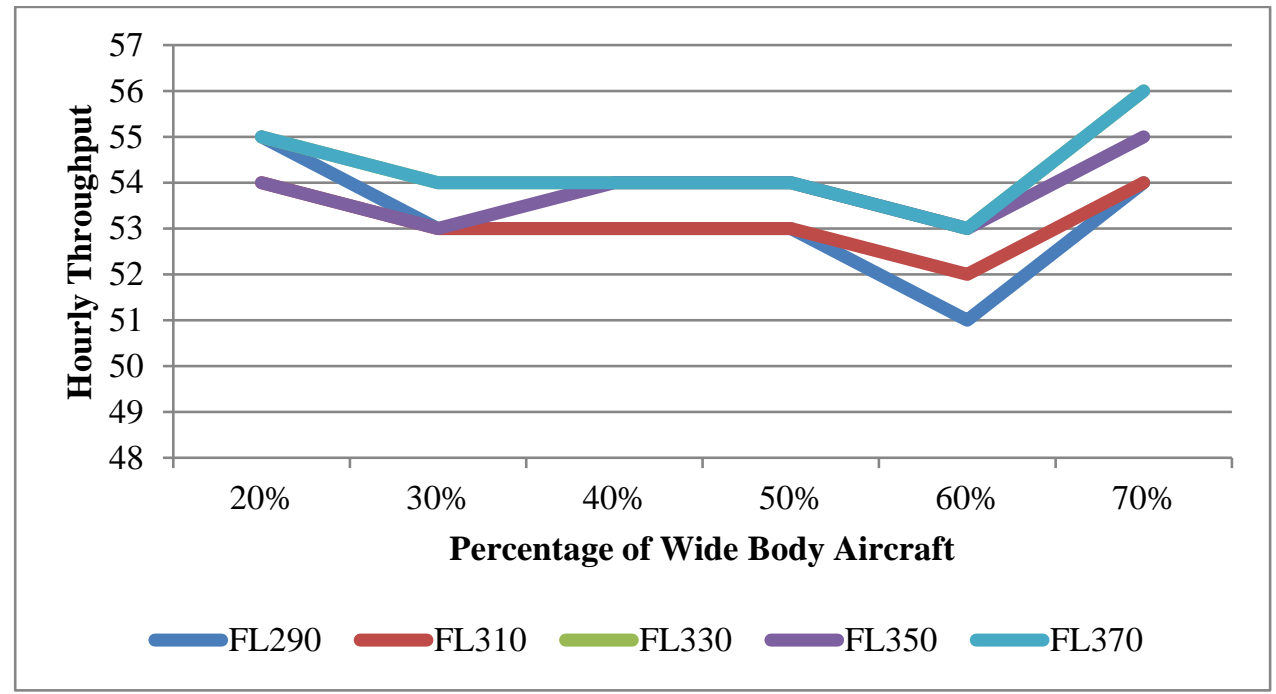

Figure 11. Sector capacities for different flight level

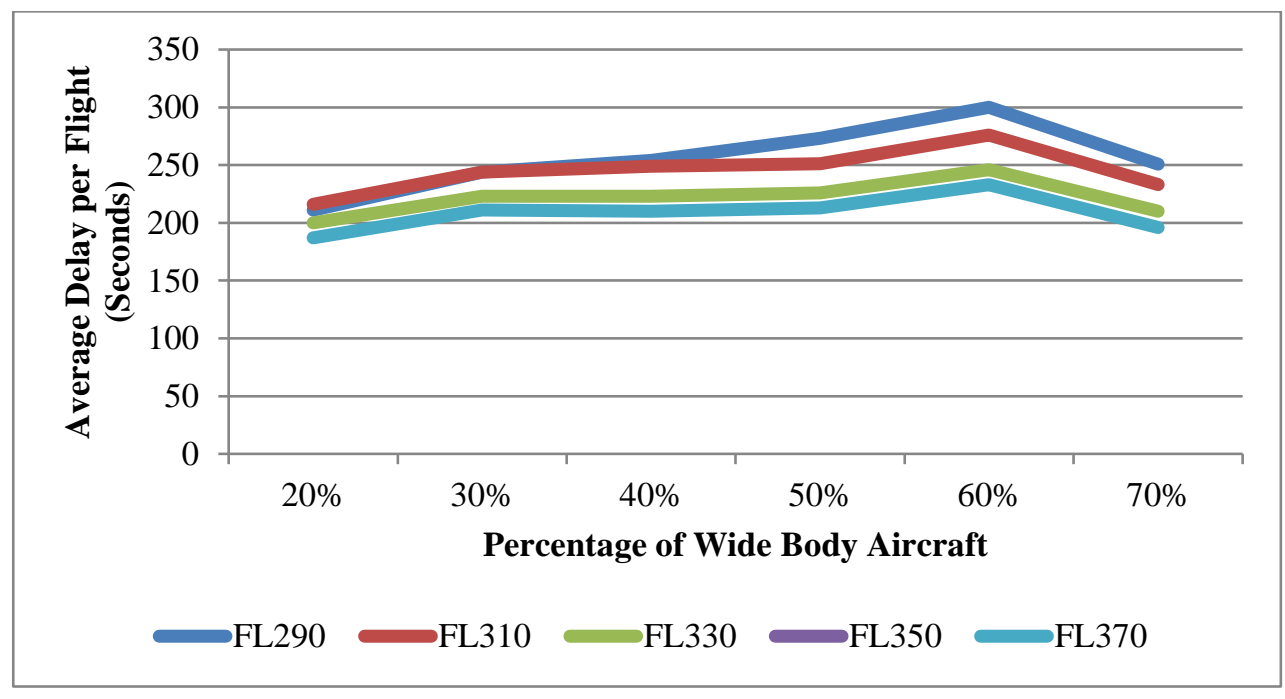

Figure 12. Average delay per aircraft for different flight level

\subsection{Alternative Scenario 1: Multiple Entry Points}

In this scenario, the throughput and average delay per aircraft are analyzed for multiple entry points for each flight level. The number of the entry points is set as 3, 4, 5 and 7 for each experiment performed for each flight level. The throughput was usually improved in every multiple entry point configuration at all flight levels up to $10 \%$ compared to baseline scenario (Figure 13-17). Multiple entry point configurations also lead to less average delays than the baseline scenario (Figure 18-22). Both throughputs and average delays strongly depend on the percentage of wide body aircraft as the number of wide body aircraft increases throughputs and average delays of multiple entry point configurations become closer to the baseline values. The best throughput improvements and delay reductions were obtained in 3 and 4 entry point configurations in this scenario. Further increase in the number of entry points (i.e. 5 and 7) did not provide significant improvements in the results. Similar to the baseline 
Çeçen and Çetek/Anadolu Univ. J. of Sci. and Technology A-Appl. Sci. and Eng. 18 (1) - 2017

scenario, $60 \%$ wide body aircraft share is the critical point because the minimum throughputs and maximum average delays were reached at this value.

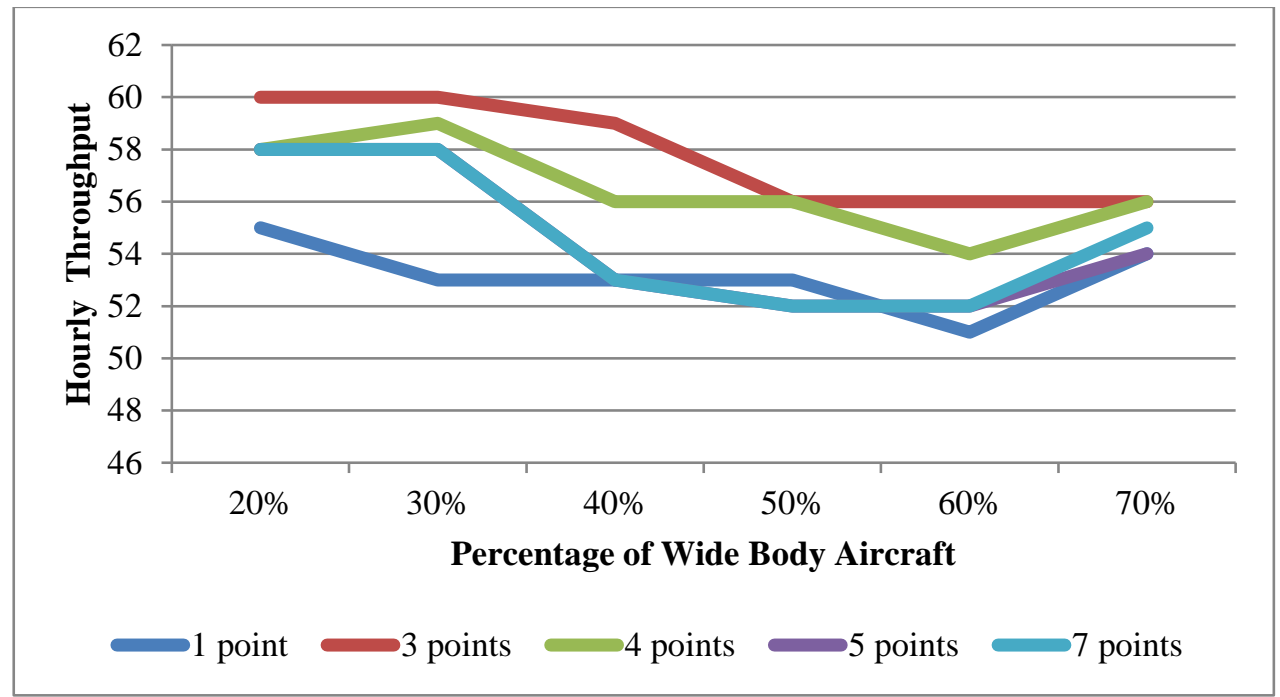

Figure 13. FL290 capacity with different distribution

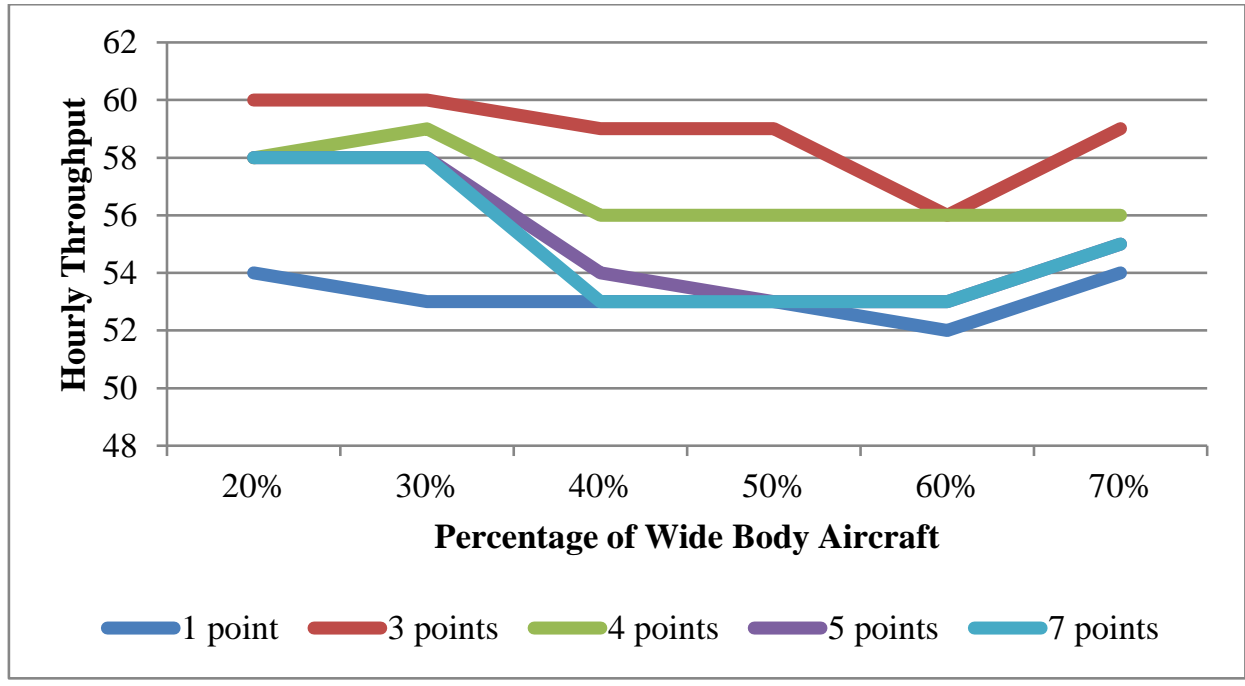

Figure 14. FL310 capacity with different distribution 
Çeçen and Çetek / Anadolu Univ. J. of Sci. and Technology A-Appl. Sci. and Eng. 18 (1) - 2017

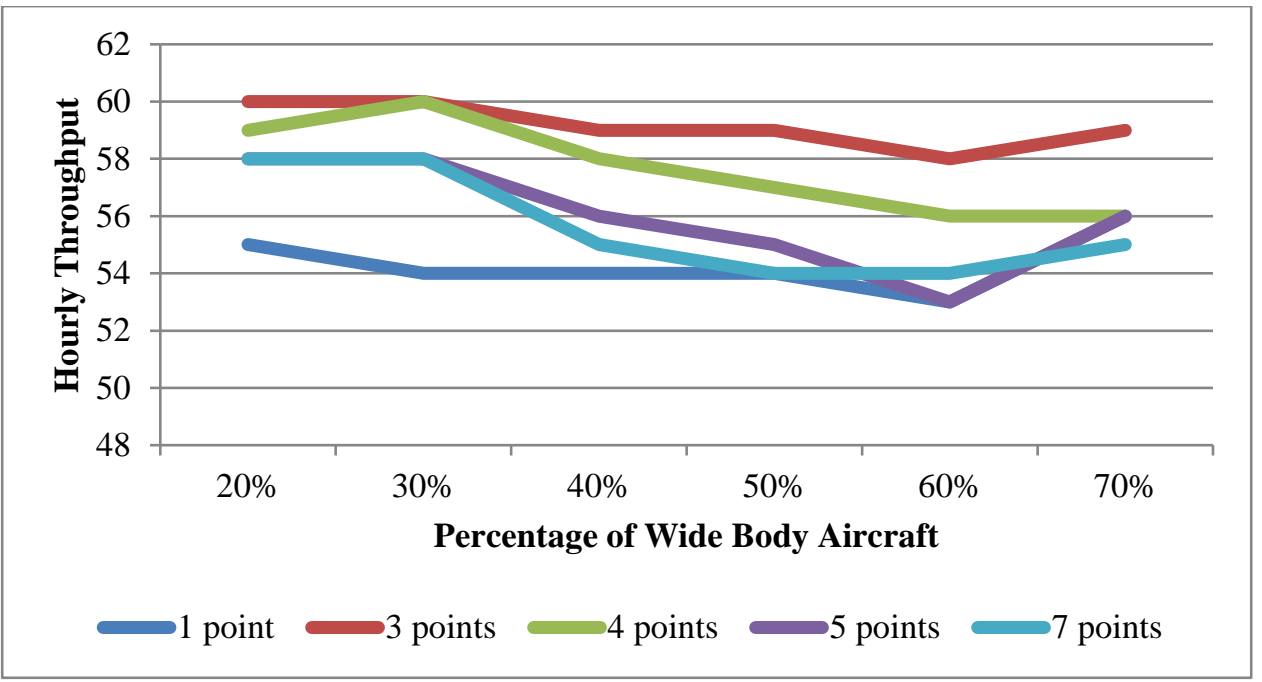

Figure 15. FL330 capacity with different distribution

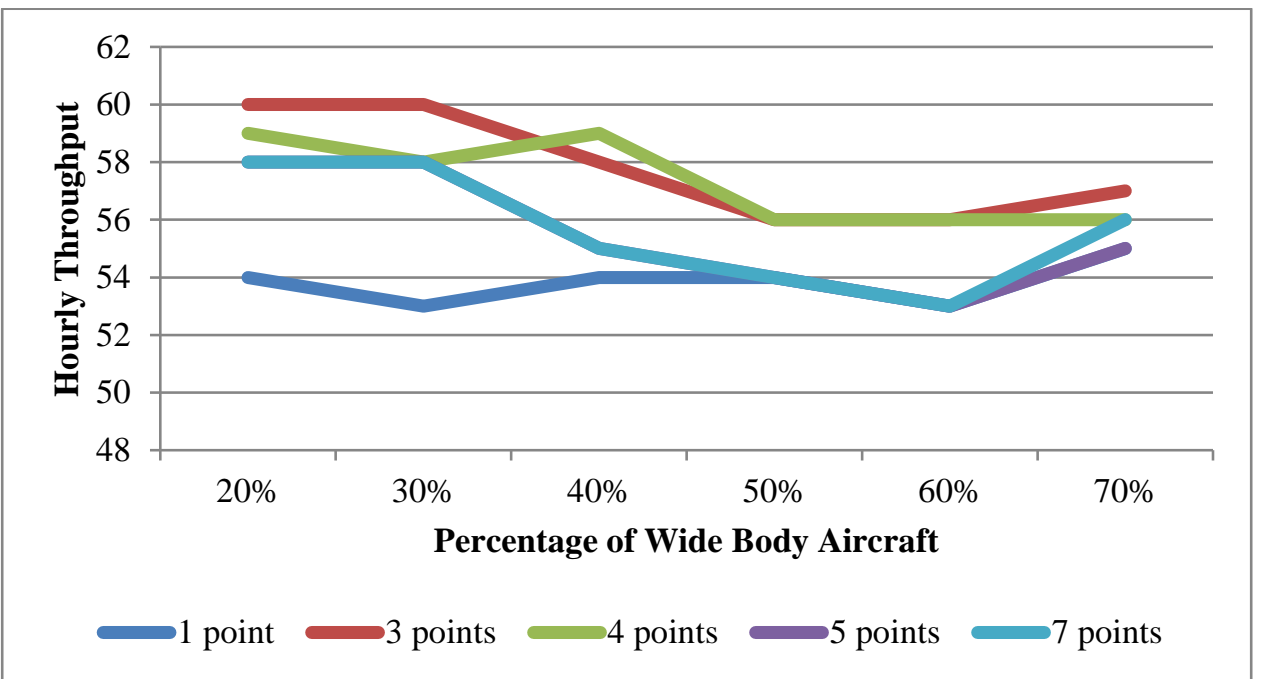

Figure 16. FL350 capacity with different distribution

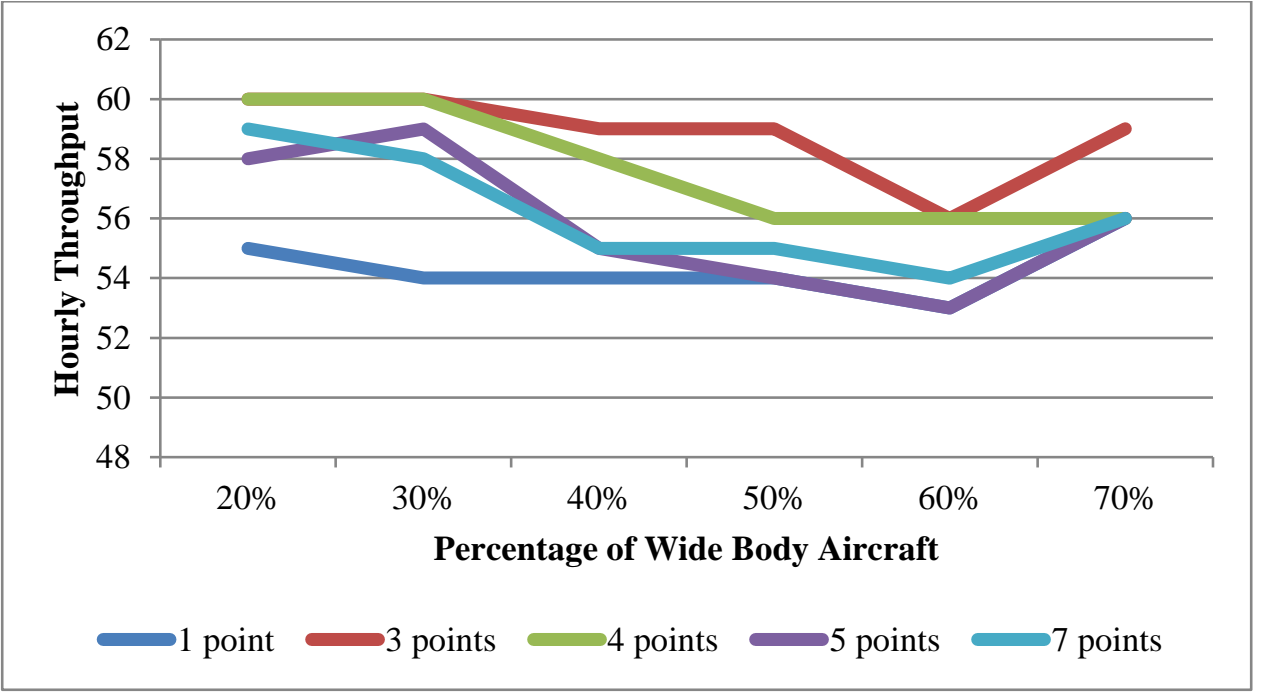

Figure 17. FL370 capacity with different distribution 
Çeçen and Çetek / Anadolu Univ. J. of Sci. and Technology A-Appl. Sci. and Eng. 18 (1) - 2017

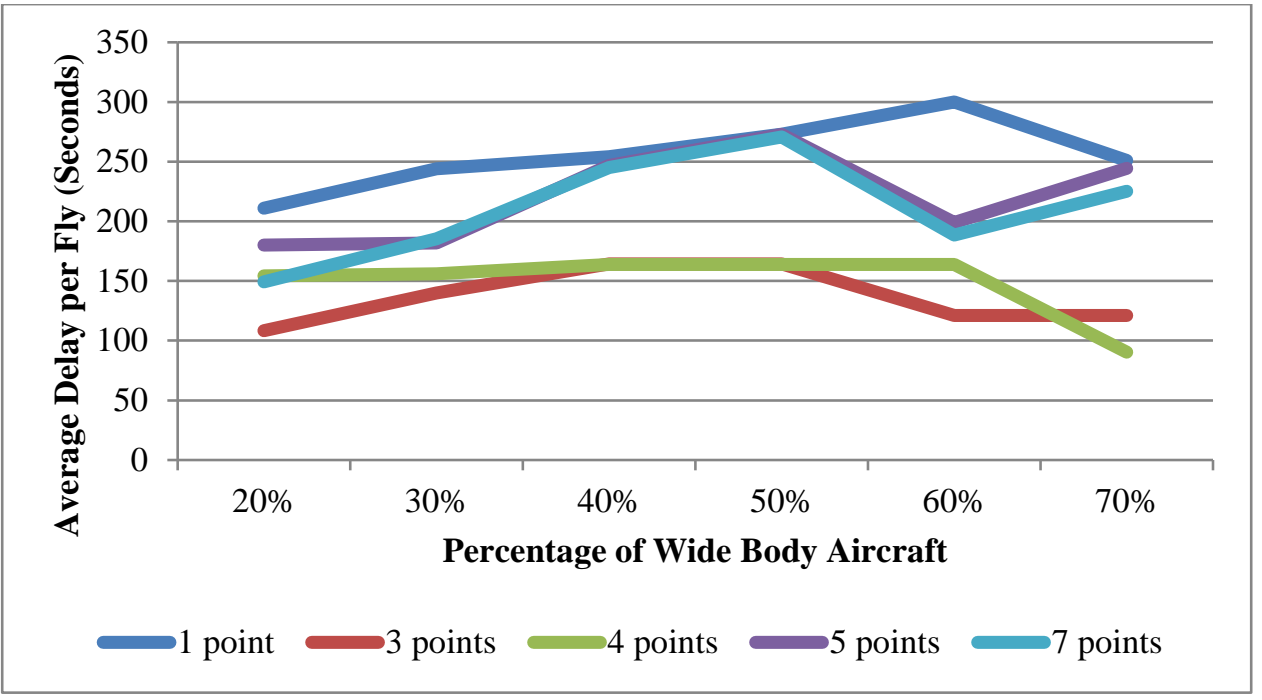

Figure 18. FL290 average delay with different distribution

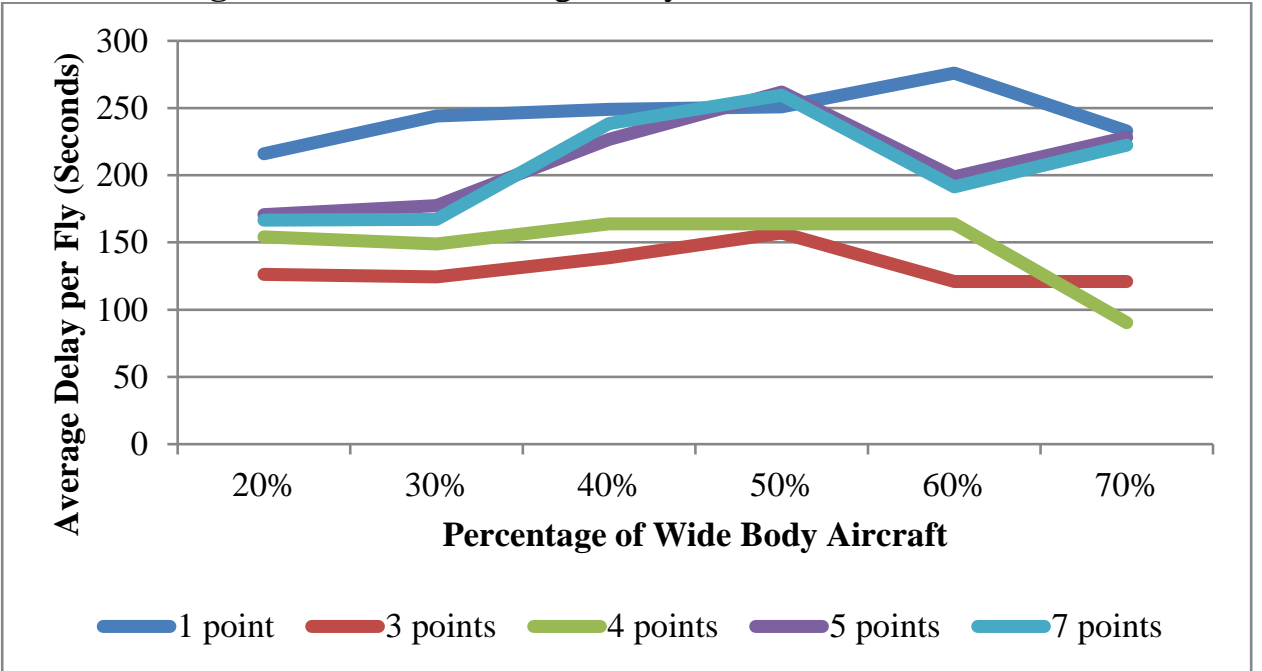

Figure 19. FL310 average delay with different distribution

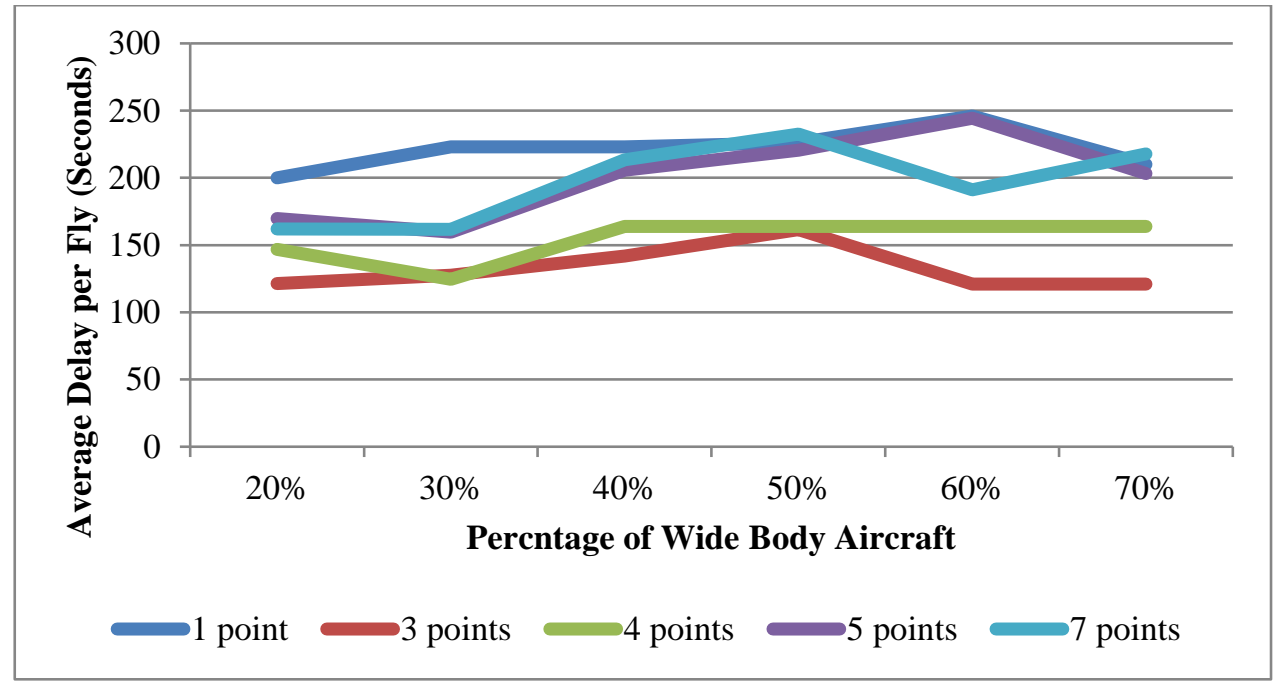

Figure 20. FL330 average delay with different distribution 
Çeçen and Çetek / Anadolu Univ. J. of Sci. and Technology A-Appl. Sci. and Eng. 18 (1)-2017

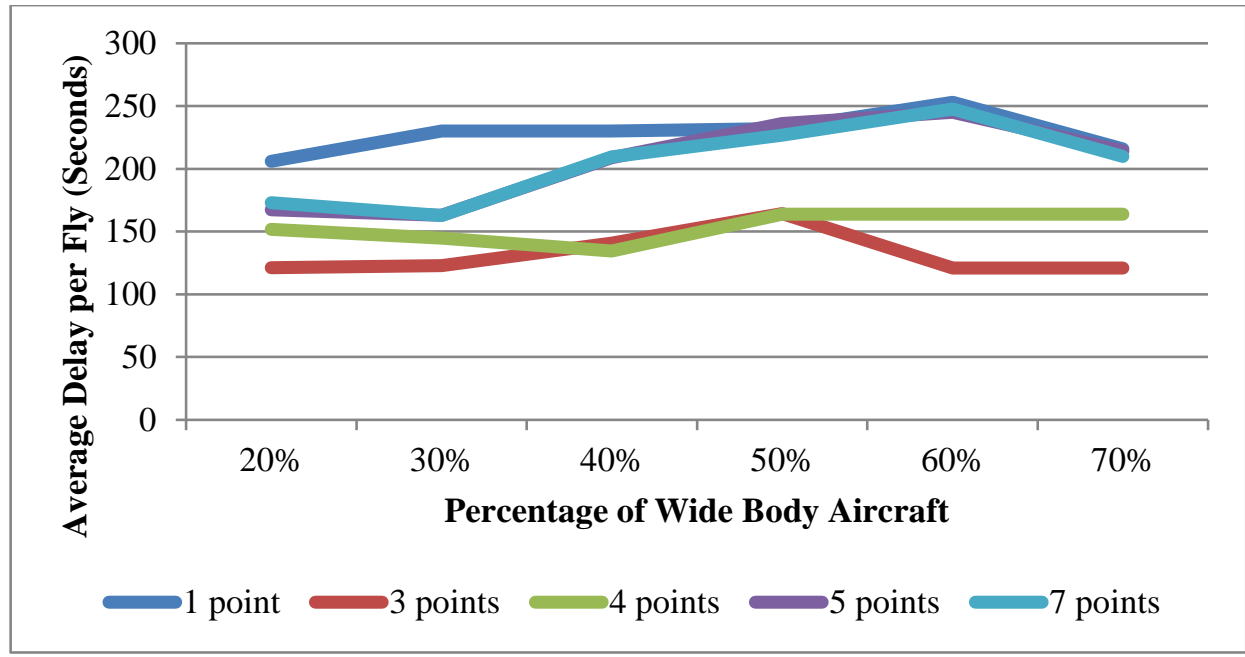

Figure 21. FL350 average delay with different distribution

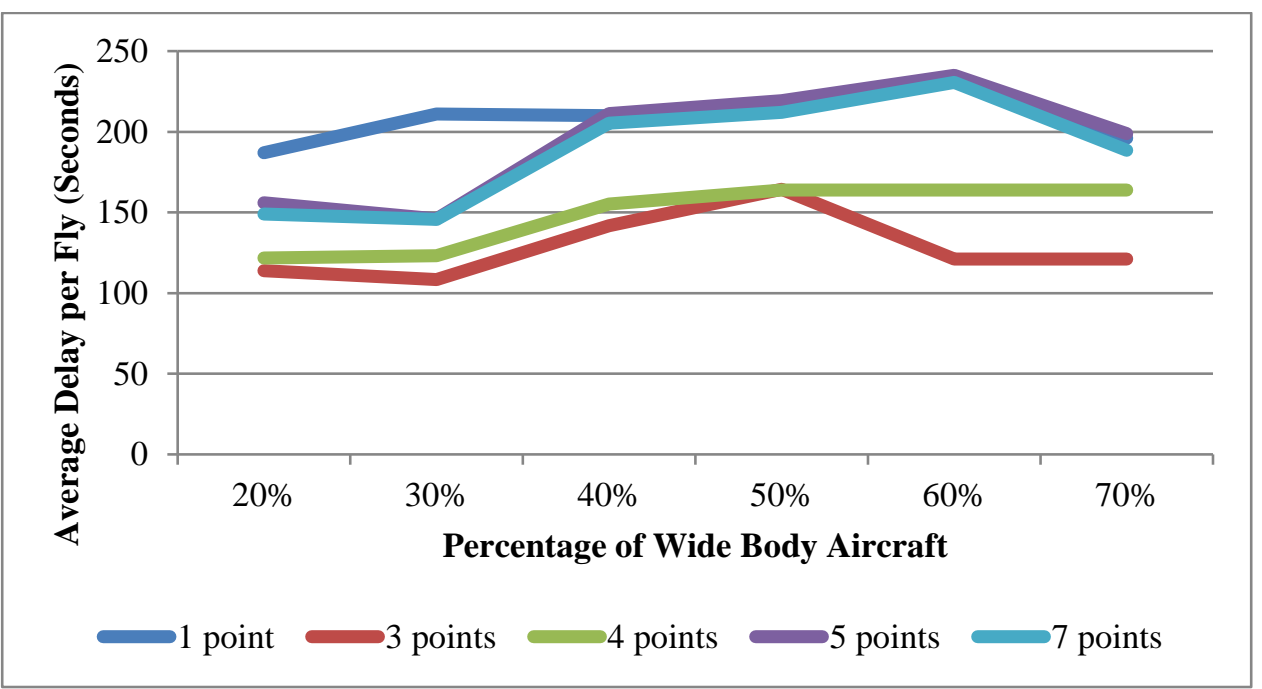

Figure 22. FL370 average delay with different distribution

\subsection{Alternative Scenario 2: Multiple Input Points with Different Spacing}

In this scenario, the sector throughput and average delay are estimated for multiple entry points with different lateral spacing (i.e. 2 to $5 \mathrm{NM}$ ). The traffic mix of wide body, narrow body and regional jets were set constant as $20 \%, 70 \%$ and $10 \%$, respectively. The throughput for each flight level was presented as a function of the number of entry points with different spacing in Figure 23-27. The best improvement in throughputs for this scenario were observed for 3 and 4 NM spacing where the hourly capacity reached up to the maximum traffic flow input of the 60 operations for 3 and 4 entry points. For FL330, the throughput 4 NM spacing increased the throughput to 60 operations per hour for all multiple entry point configurations. Similarly, $5 \mathrm{NM}$ spacing provided the same maximum throughput for all multiple entry points at FL370. The average delays were nearly reduced to half compared to the baseline scenario when the configuration of 4 entry points with 4NM spacing was used for all flight levels (Figure 28-32). 
Çeçen and Çetek / Anadolu Univ. J. of Sci. and Technology A-Appl. Sci. and Eng. 18 (1) - 2017

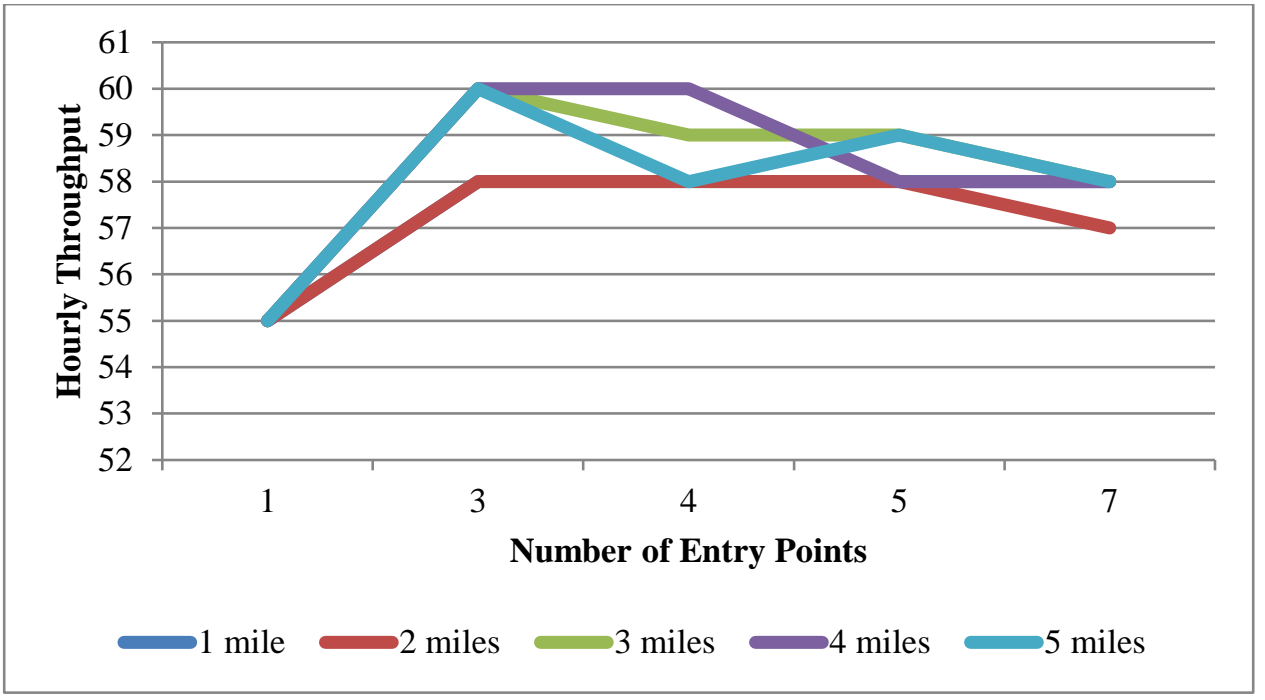

Figure 23. FL290 capacity with multiple input points

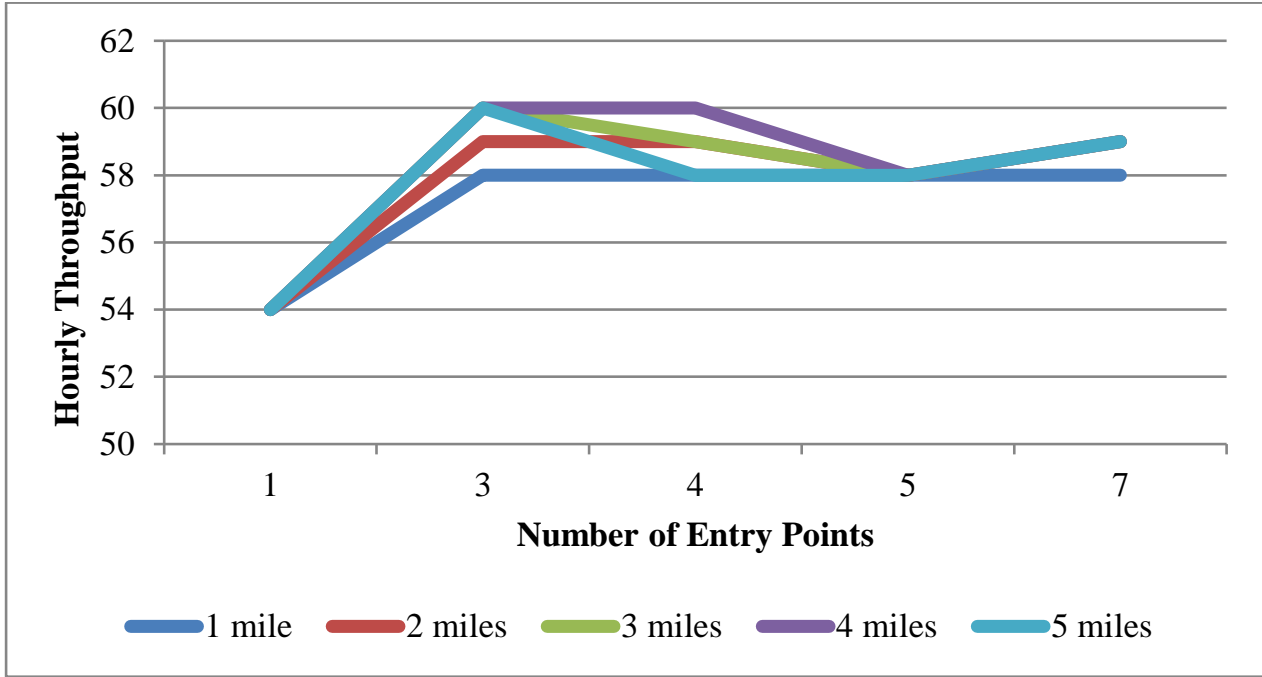

Figure 24. FL310 capacity with multiple input points

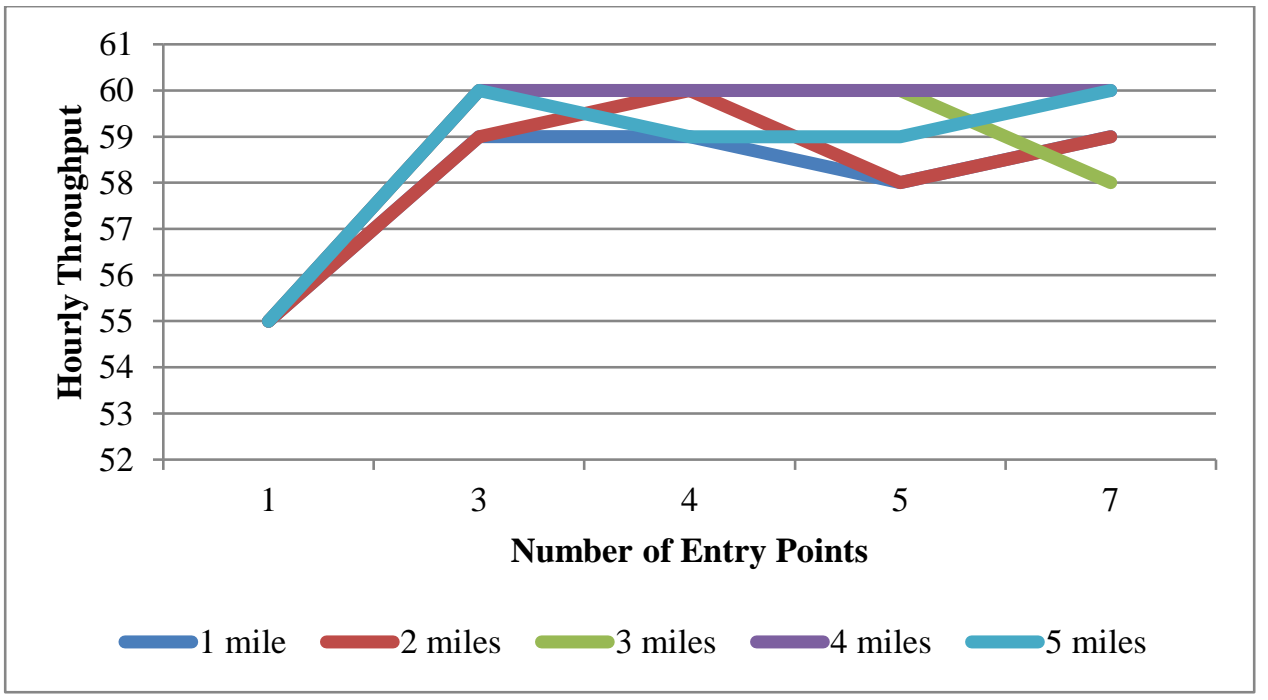

Figure 25. FL330 capacity with multiple input points 
Çeçen and Çetek / Anadolu Univ. J. of Sci. and Technology A-Appl. Sci. and Eng. 18(1)-2017

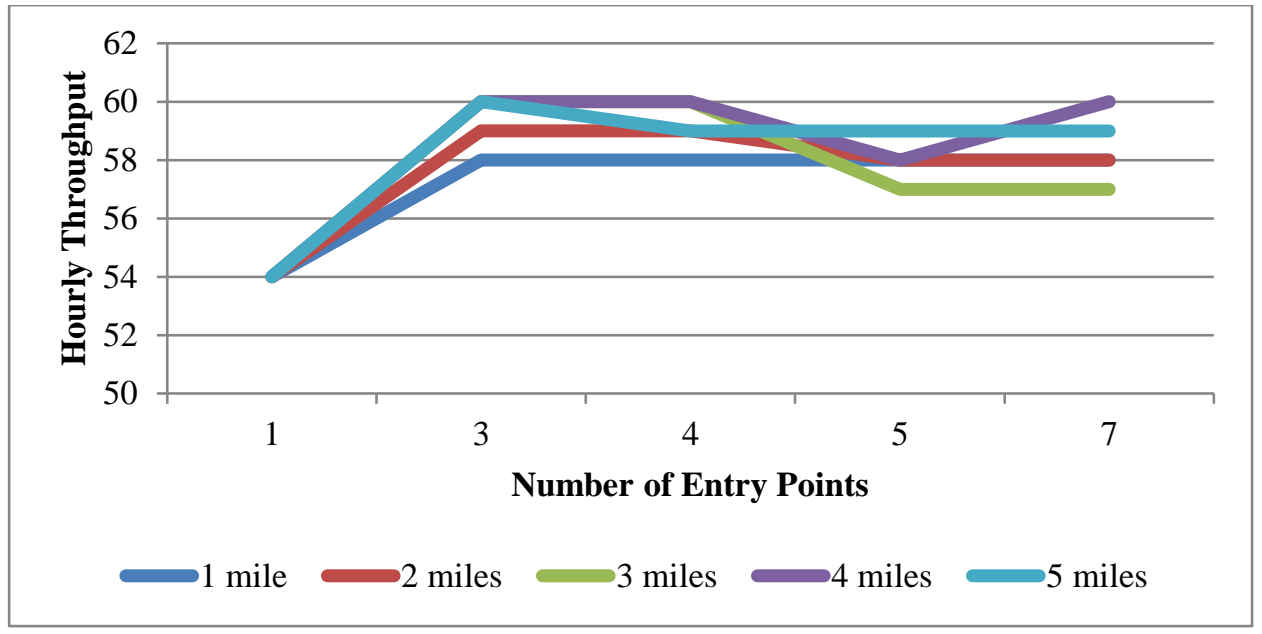

Figure 26. FL350 capacity with multiple input points

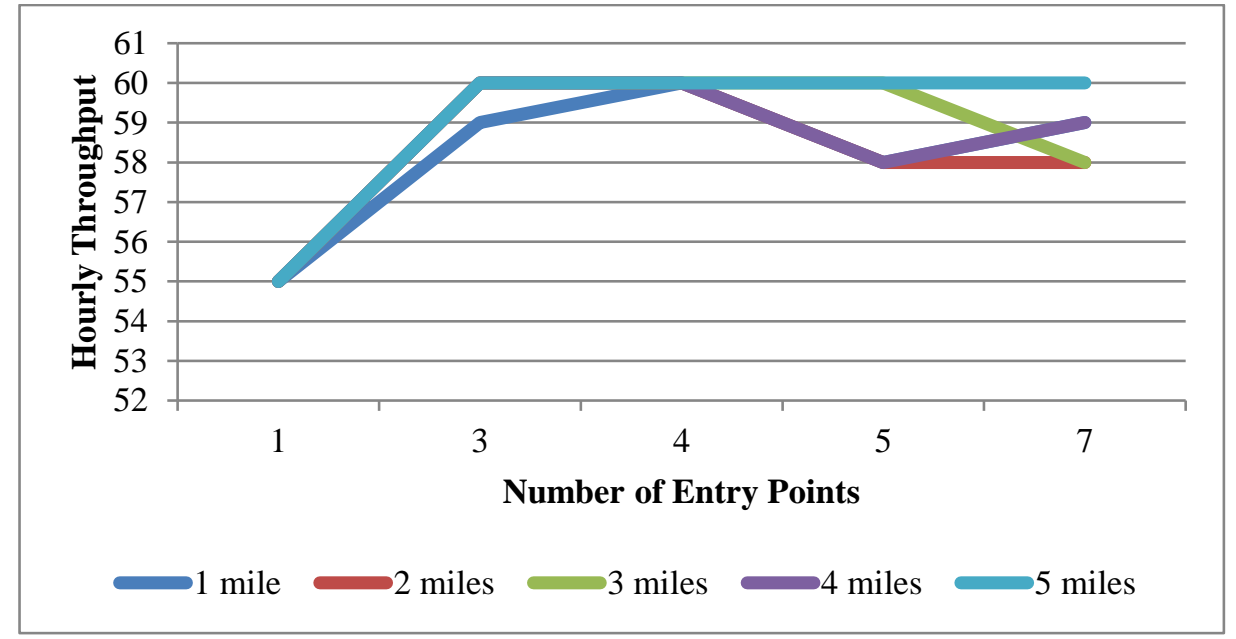

Figure 27. FL370 capacity with multiple input points

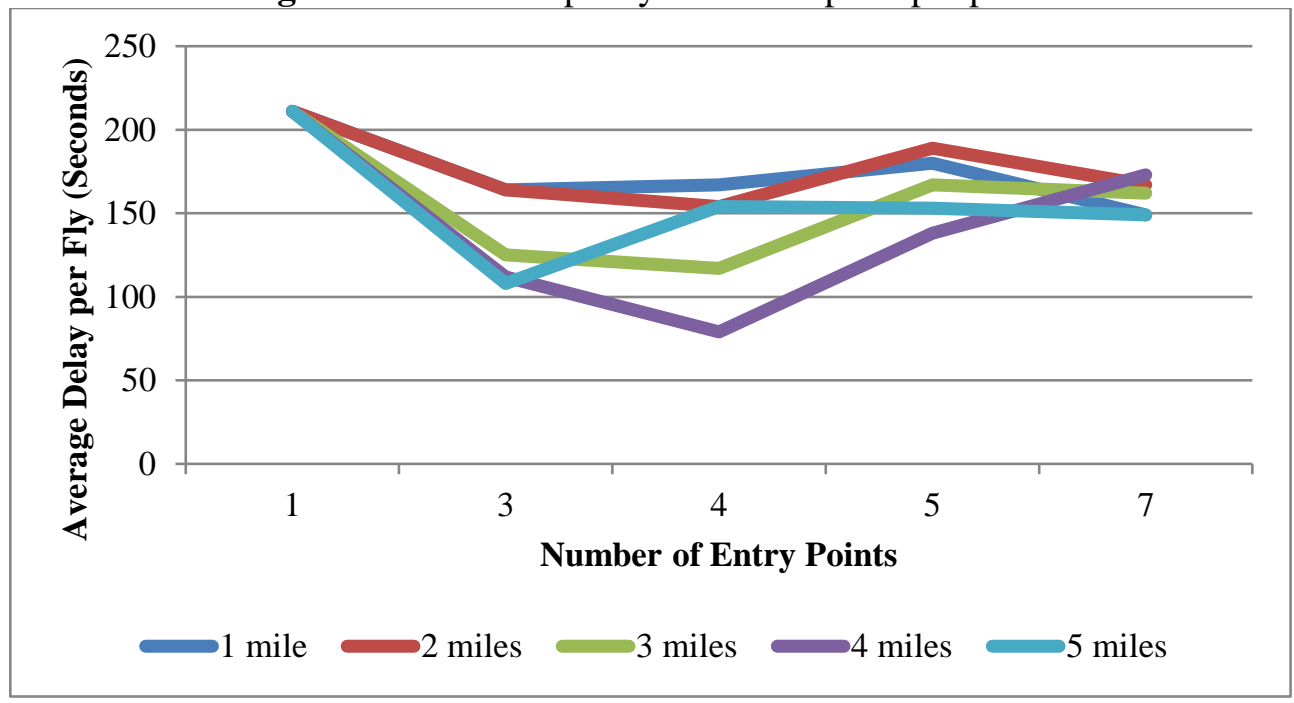

Figure 28. FL290 average delay with multiple input points 
Çeçen and Çetek / Anadolu Univ. J. of Sci. and Technology A-Appl. Sci. and Eng. 18(1)-2017

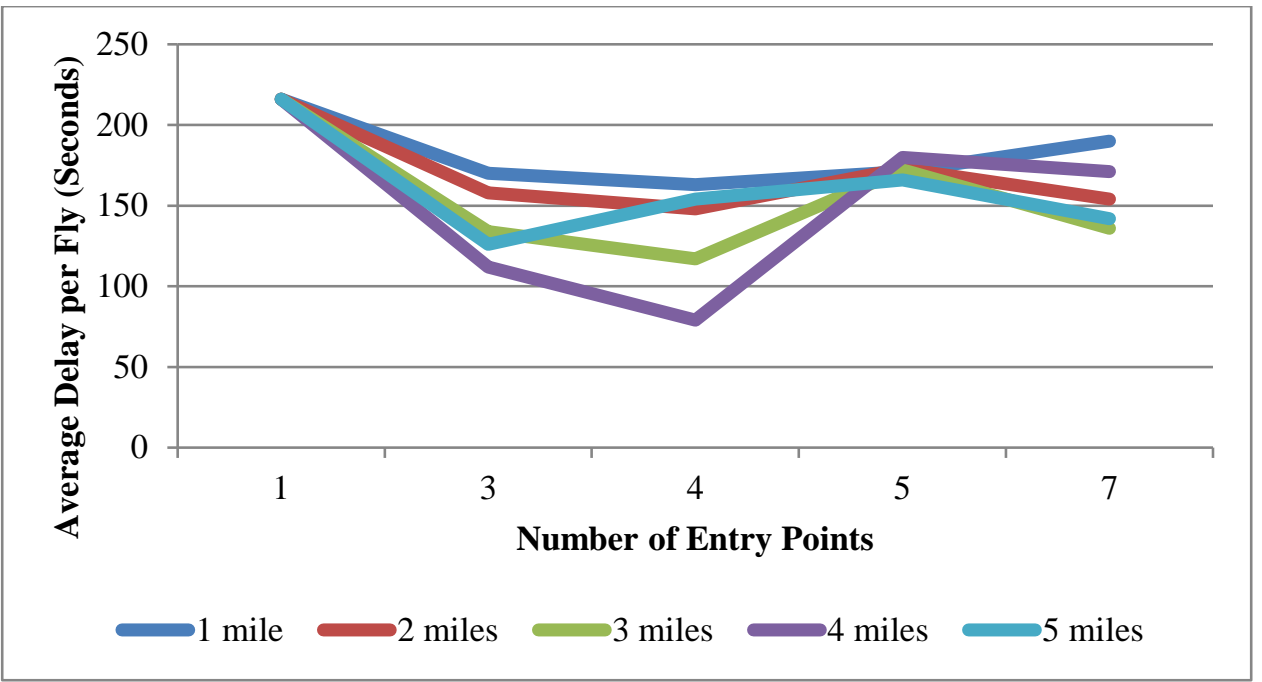

Figure 29. FL310 average delay with multiple input points

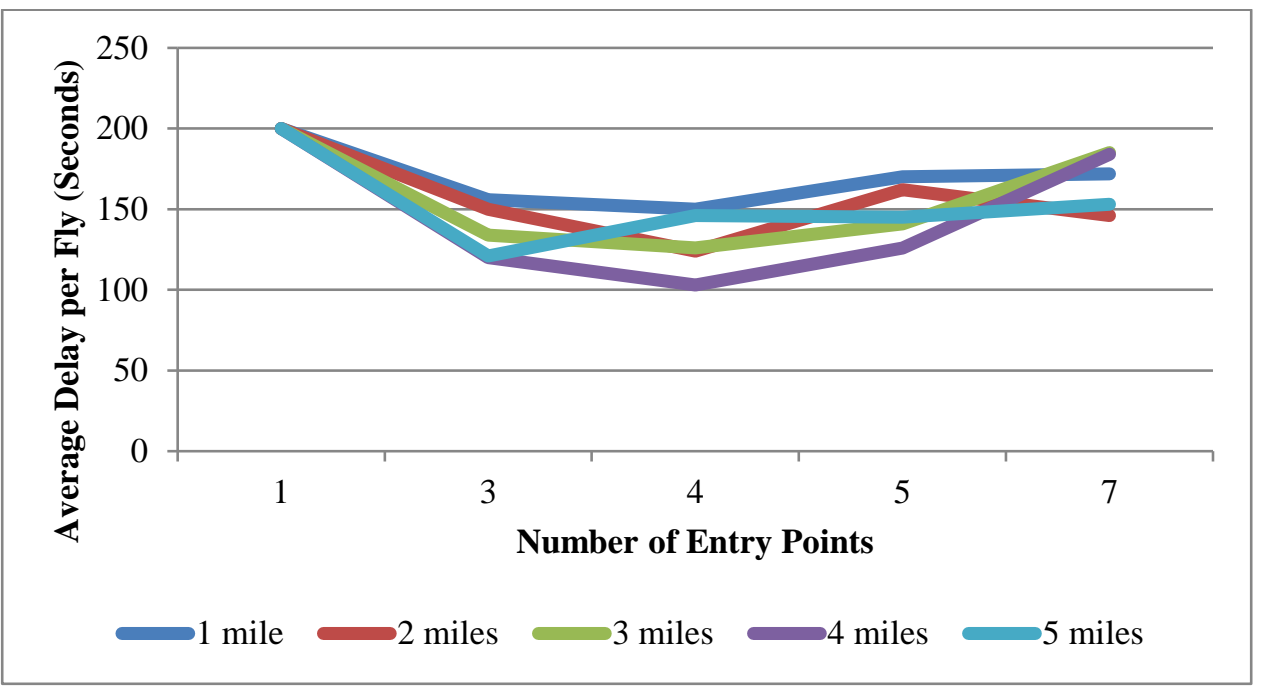

Figure 30. FL330 average delay with multiple input points

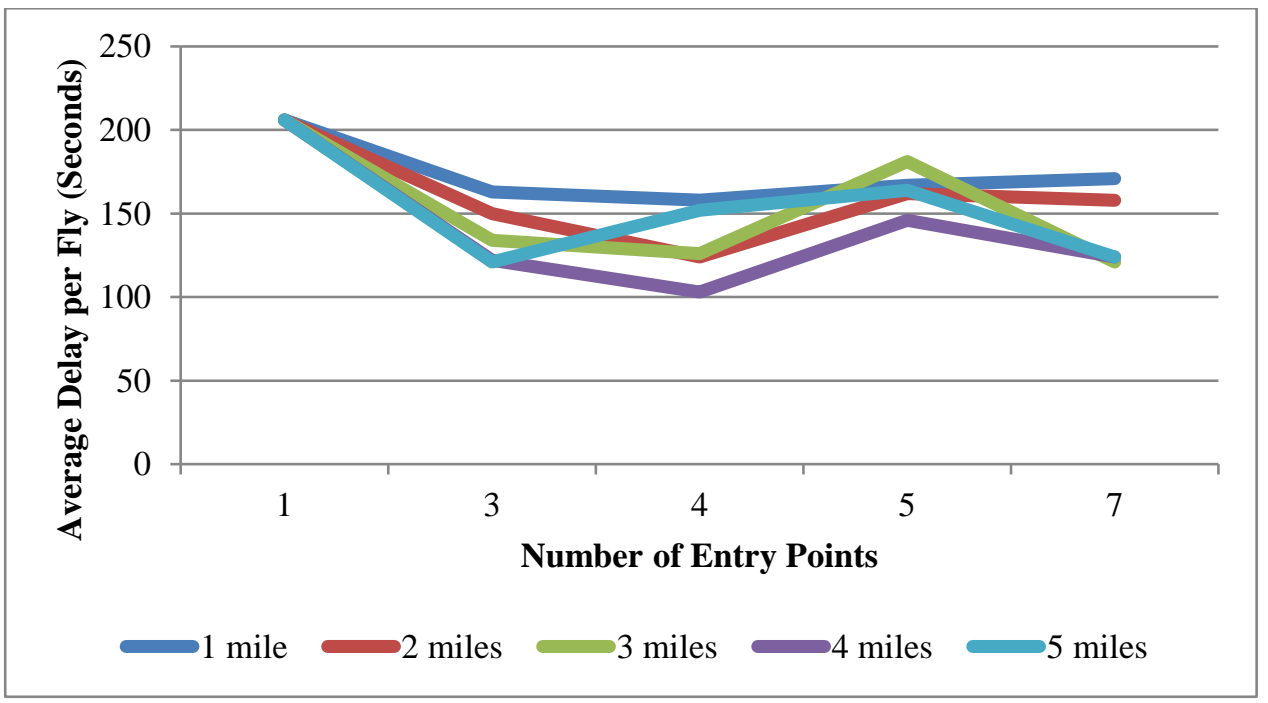

Figure 31. FL350 average delay with multiple input points 
Çeçen and Çetek / Anadolu Univ. J. of Sci. and Technology A-Appl. Sci. and Eng. 18 (1)-2017

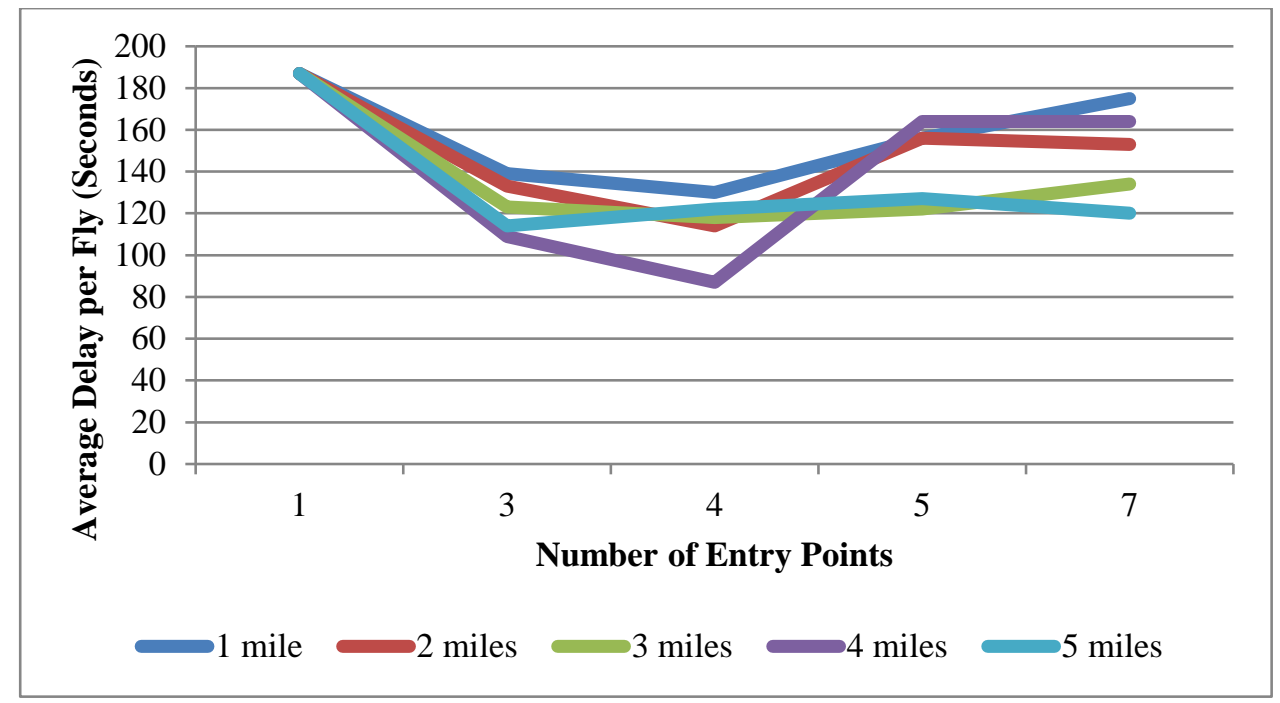

Figure 32. FL370 average delay with multiple inputs

\section{CONCLUSIONS}

The assignment of best sector entry points among multiple alternatives for each aircraft sequence provides greater flexibility in air traffic flow and capacity management than the current single and fixed sector entry point configuration because it allows significant reductions in conflict resolution times between aircraft through the change of encounter geometry in the horizontal plane. The proposed assignment approach based on genetic algorithms searches for optimal entry-point combinations for arriving aircraft sequences to minimize conflict resolution times. Therefore, airborne delays can be reduced and the hourly sector throughput can be increased considerably compared to the baseline configuration under the similar traffic situations such as traffic density, sector geometry, aircraft mix and flight levels. The use of such an approach in a decision support tool can also help air traffic controllers find efficient resolutions for aircraft conflicts with less mental workload and reduce the number and transmission time of these resolution commands to aircraft. The assignment algorithm can also offer an important insight to airspace designers to determine the optimum number of entry points and spacing between them for the given traffic density and complexity. In order to achieve more thorough analysis of capacity and traffic flow, aircraft maneuvering models (i.e. heading and speed changes) and inaccuracies of navigation aids will be included in the algorithm in future studies. Besides, a metaheuristic approach can be adapted to the assignment algorithm in order to provide faster convergence time to optimal solution for higher number of gates and more complex sector geometries.

\section{REFERENCES}

[1] Aybek Cetek F, Cetek C. Simulation modelling of runway capacity for flight training airports. The Aeronaut J 2014; 118:143-154.

[2] Airbus. Delivering the Future - Global Market Forecast 2011-2030. Blagnac Cedex, France: Airbus, 2011.

[3] Boeing. Current Market Outlook 2011-2030. Seattle, WA, USA: Boeing, 2011.

[4] ICAO. Global and Regional 20 Year Forecasts - Pilots, Maintenance Personnel - Air Traffic Controllers. Doc 9956. Montreal, Canada: International Civil Aviation Organization Publications, 2011.

[5] Cavcar A. Temel Hava Trafik Yönetimi. Eskişehir, Türkiye: Anadolu Universitesi Yayınları, 1998. 
Çeçen and Çetek/Anadolu Univ. J. of Sci. and Technology A-Appl. Sci. and Eng. 18 (1) - 2017

[6] ICAO. Annex 11 Air Traffic Services, Montreal, Canada: International Civil Aviation Organization Publications, 2001.

[7] Janić M. Air Transport System Analysis and Modelling. Amsterdam, The Netherlands: Gordon Breach Science Publishers, 2000.

[8] Aybek Cetek F. A simulation model proposal for dynamic gate assignment in terminal control areas. $\mathrm{PhD}$, Anadolu University, Eskisehir, Turkey, 2015 (thesis in Turkish with an abstract in English).

[9] Janić M, Tošić V. (1991). En route sector capacity model. Transport Sci 1991; 25: 299-307.

[10] Barnhart C, Smith B. Quantitative Problem Solving Methods in the Airline Industry. New York, NY, USA: Springer, 2012.

[11] Odoni AR. The flow management problem in air traffic control. In Odoni AR, Bianco L, Szegö G, editors. Flow Control of Congested Networks. Berlin, Germany: Springer, 1987. pp. 269-288.

[12] Terrab M, Odoni AR. Strategic flow management for air traffic control. Oper Res 1993; 41:138152.

[13] Richetta O, Odoni AR. Solving optimally the static ground-holding policy problem in air traffic control. Transport Sci 1993; 27: 228-238.

[14] Richetta O, Odoni AR. Dynamic solution to the ground-holding problem in air traffic control. Transport Res A-Pol 1994; 28: 167-185.

[15] Vranas PBM, Bertsimas D, Odoni AR. Dynamic ground-holding policies for a network of airports. Transport Sci 1994; 28: 275-291.

[16] Mukherjee A, Hansen M. (2007). A dynamic stochastic model for the single airport ground holding problem. Transport Sci 2007; 41: 444-456.

[17] Mao Z-H, Feron E, Bilimoria, K. Stability and performance of intersecting aircraft flows under decentralized conflict avoidance rules. IEEE T Intell Transp 2001; 2: 101-109.

[18] Dugail D, Feron E, Bilimoria K. Stability of intersecting aircraft flows using heading change maneuvers for conflict avoidance. In: IEEE 2002 American Control Conference; 8-10 May 2002; Anchorage, AK, USA. Evanston, IL, USA: IEEE. vol 1. pp. 760-766.

[19] Wang T-C, Li Y-J. Optimal scheduling and speed adjustment in en route sector for arriving airplanes. J Aircraft 2011; 48: 673-682.

[20] Allignol C, Barnier N, Durand N, Alliot JM. A new framework for solving en-route conflicts. In ATM 2013 10th USA/Europe Air Traffic Management Research and Development Seminar; 10-13 June 2013; Chicago, IL, USA. Red Hook, NY, USA: Curran Associates. pp 371-379.

[21] Cetek C. Realistic speed change maneuvers for air traffic conflict avoidance and their impact on aircraft economics. International Journal of Civil Aviation 2009; 1:62-73.

[22] Jones J, Lovell DJ, Ball MO. En route speed control methods for transferring terminal delay. In ATM 2013 10th USA/Europe Air Traffic Management Research and Development Seminar; 10-13 June 2013; Chicago, IL, USA. Red Hook, NY, USA: Curran Associates. pp. 564-573. 
[23] Bertsimas D, Patterson SS. The air traffic flow management problem with enroute capacities. Oper Res 1998; 46: 406-422.

[24] Bertsimas D, Patterson SS. The traffic flow management rerouting problem in air traffic control: a dynamic network flow approach. Transport Sci 2000; 34: 239-255.

[25] Dell'Olmo P, Lulli G. A dynamic programming approach for the airport capacity allocation problem. IMA Journal of Management Mathematics 2003; 14: 235-249.

[26] Agust1 A, Alonso-Ayuso A, Escudero L, Pizarro C. On air traffic flow management with rerouting part 1: deterministic case. Eur J Oper Res 2012; 219: 156-166.

[27] Agustı A, Alonso-Ayuso A, Escudero L, Pizarro C. On air traffic flow management with rerouting part 2: stochastic case. Eur J Oper Res 2012; 219: 167-177.

[28] Delahaye D, Alliot JM, Schoenauer M, Farges JL. Genetic algorithms for partitioning air space. In IEEE 10th Conference on Artificial Intelligence for Applications: 1-4 March 1994; San Antonio, TX, USA: IEEE. pp 291-297.

[29] Yousefi A, Donohue GL, Sherry L. High-volume tube-shape sectors (HTS): a network of high capacity ribbons connecting congested city pairs. In DASC04 the $23^{\text {rd }}$ Digital Avionics Systems Conference; 24-28 October 2004; Salt Lake City, UT, USA. Madison, WI, USA: Omnipress. vol 1. pp 3.C.1-1-3C.1-7.

[30] Mitchell JSB, Sabhnani G, Krozel J, Hoffman B, Yousefi A. Dynamic airspace configuration management based on computational geometry techniques. In AIAA Guidance, Navigation, and Control Conference and Exhibit; 18-21 August 2008; Honolulu, Hawaii, USA: AIAA.

[31] Xue M. Airspace sector redesign based on Voronoi diagrams. Journal of Aerospace Computing, Information, and Communication 2009; 6: 624-634.

[32] Basu A, Mitchell JSB, Sabhnani GK. Geometric algorithms for optimal airspace design and air traffic controller workload balancing. Journal of Experimental Algorithmics 2009; 14: Article No.3.

[33] Zhang DF, Chen YZ, Bi H, Song ZX. Airspace sectorization based on weighted graph spectral bisection algorithm. In: The12th COTA International Conference of Transportation Professionals; 3-6 August 2012; Beijing, China. Reston, VA, USA: ASCE. pp 1924-1935.

[34] Bubalo B, Daduna JR. Airport capacity and demand calculations by simulation - the case of BerlinBrandenburg International Airport. NETNOMICS 2011; 12: 161-181.

[35] ICAO. Rules of the Air and Air Traffic Services, Air Traffic Management. 15th ed. Montreal, Canada: International Civil Aviation Organization Publications, 2007.

[36] Eurocontrol. User Manuel for the Base of Aircraft Data (BADA). Rev. 3.5. Brétigny-sur-Orge Cedex, France: Eurocontrol, 2002.

[37] Eurocontrol. Coverage of 2013 European Air Traffic for the Base of Aircraft Data. Brétigny-surOrge Cedex, France: Eurocontrol, 2015.

[38] Gen M, Cheng R. Genetic Algorithms and Engineering Optimization. New York, NY, USA: John Wiley \& Sons, 2000. 